\title{
Geoquímica dos diques máficos da região leste da Província Aurífera Alta Floresta: inferências sobre a fonte mantélica e implicações geodinâmicas
}

\author{
Geochemistry of mafic dykes of the East region of Alta Floresta Gold \\ Province: inferences on their mantle sources and geodynamic implications
}

\author{
Guilherme Mene Ale Primo ${ }^{1,2}$ (D), Paulo César Corrêa da Costa ${ }^{1,2}$ (D), Vicente Antonio Vitorio Girardi ${ }^{3}$ (D) \\ 'Universidade Federal de Mato Grosso - UFMT, Faculdade de Geociências - FAGEO, Programa de Pós-graduação \\ em Geociências, Av. Fernando Corrêa da Costa, 2.367, CEP 78060-900, Boa Esperança, Cuiabá, MT, BR \\ (guilherme.ale.primo@live.com; pccorrea.costa@gmail.com) \\ 2Universidade Federal de Mato Grosso - UFMT, Faculdade de Geociências - FAGEO, Grupo de Pesquisa \\ Magmatismo de Mato Grosso - MAGMATO, Cuiabá, MT, BR. \\ 3Universidade de São Paulo - USP, Instituto de Geociências, São Paulo, SP, BR (girardi@usp.br)
}

Recebido em 3 de junho de 2019; aceito em 9 de setembro de 2020

\begin{abstract}
Resumo
O enxame de diques máficos de Peixoto de Azevedo e Nova Guarita, região Leste da Província Aurífera Alta Floresta (PAAF), compõe-se de basaltos toleíticos evoluídos. Tais rochas provêm de fonte enriquecida por fluidos originados durante a subducção de crosta oceânica recoberta por significativa quantidade de sedimentos de composição semelhante à média global de sedimentos subductados (global subducting sediment composition - GLOSS). O enxame de diques intrude granitos e gnaisses paleoproterozoicos dos arcos magmáticos Cuiú-Cuiú e Juruena, e possui idade de 1419 Ma. No Cráton Amazônico, suas características geoquímicas relacionadas à sua origem mantélica são muito semelhantes às dos diques máficos de Carajás e da Suíte Máfica Vespor, ambos paleoproterozoicos. São semelhantes em idade quando comparados aos diques de Nova Lacerda, assim como de outras regiões do Supercontinente Columbia, como os diques Bas Drâa Inlier, a W do Cráton da África, a soleira Midsommerso, a NE da Groenlândia, e os diques Michael Gabbro, na Província Grenville, no Canadá. Essas intrusões ocorreram entre 1,42 e 1,33 Ga, durante as fases finais de fragmentação do Supercontinente Columbia.
\end{abstract}

Palavras-chave: Cráton Amazônico; Diques máficos; Geoquímica; Manto.

\begin{abstract}
The mafic dyke swarm from the Peixoto de Azevedo and Nova Guarita, Eastern region of the Alta Floresta Gold Province (AFGP) is composed of tholeiitic evolved basalts originated from enriched mantle source, due to the action of metasomatic fluids from a subducted oceanic crust overlaid by significant amounts of GLOSS- type material. The swarm intrudes Paleoproterozoic granites and gneisses from the Cuiú-Cuiú and Juruena magmatic arcs at 1,419 Ma. In the Amazonian Craton, its geochemical characteristics related to the mantle source are very similar to those from the Paleoproterozoic Carajás mafic dykes and Vespor mafic suite. Compared to other dykes swarms of similar age and origin, it is comparable to the dykes of Nova Lacerda, as well as other regions of the Columbia Supercontinent, such as the Bas Drâa Inlier dams to the $\mathrm{W}$ of the Craton of Africa, the Midsommerso sill to the NE of Greenland and the Michael Gabbro levees, in Grenville Province, Canada. These intrusions yielded ages from 1.42 to $1.33 \mathrm{Ga}$, during the last phases of the Supercontinent Columbia break-up.
\end{abstract}

Keywords: Amazonian Craton; Mafic dykes; Geochemistry; Mantle. 


\section{INTRODUÇÃO}

O estudo de enxames de diques tem sido abordado por diversos autores para descrever processos que envolvem evolução mantélica no tempo e no espaço, utilizando mecanismos e processos tectônicos, tais como aberturas de oceanos e rupturas continentais (Halls, 1982; Bossi et al., 1993; Bellieni et al., 1995; Mazzucchelli et al., 1995, 2000; Rivalenti et al., 1995; Iacumin et al., 2001, 2003).

No contexto da Plataforma Sul-Americana, diversos trabalhos buscam caracterizar enxames de diques, principalmente em segmentos cratônicos, como o Cráton São Francisco, descrevendo a petrologia, a geoquímica e a geocronologia dos diques de idade Meso a Paleoproterozoica (Moraes Brito et al., 1989; Bastos Leal et al., 1994; Bellieni et al., 1995; Menezes Leal et al., 1995; Mazzucchelli et al., 2000; Corrêa da Costa et al., 2006; Girardi et al., 2017). No Cráton Amazônico, alguns autores apresentam dados que auxiliam o entendimento dos processos geodinâmicos e a origem de seus mantos parentais (Silva et al., 1980; Rivalenti et al., 1998; Santos et al., 2000; Menezes Leal et al., 2000; Teixeira et al., 2006; Corrêa da Costa et al., 2008, 2009; Teixeira et al., 2011; Girardi et al., 2013; Teixeira et al., 2016; Trindade Netto et al., 2016; Teixeira et al., 2019; Giovanardi et al., 2019). A partir da compilação de dados geocronológicos, geotectônicos e paleomagnéticos, diversos trabalhos relacionam o estudo de diques com possíveis rupturas de paleocontinentes (Bispo-Santos et al., 2008; Teixeira et al., 2011; Bispo-Santos et al., 2012; Ernst, 2013; Ernst e Buchan, 2001; D'Agrella Filho et al., 2015; Teixeira et al., 2016; Ernst et al., 2016).

Este trabalho abrange a região leste da Província Aurífera Alta Floresta (PAAF), porção centro-sul do Cráton Amazônico, formado pelo Arco Magmático Cuiú-Cuiú (Klein et al., 2001; Vasquez et al., 2002; Assis et al., 2017) e pelo Arco Magmático Juruena (Duarte et al., 2012; Scandolara et al., 2014). Tais arcos magmáticos estão relacionados à evolução do Supercontinente Columbia ou Nuna, de idade PaleoMesoproterozoica (Hoffman, 1989; Rogers e Santosh, 2002; Pesonen et al., 2003; Bispo-Santos et al., 2012; D'AgrellaFilho et al., 2012, 2015, 2016).

O presente trabalho foi fundamentado principalmente em dados petrográficos e geoquímicos, e visou estudar a origem e os processos petrogenéticos atinentes à formação dos enxames de diques em questão. Procurou-se também obter, por meio de comparações com enxames de diques do Cráton Amazônico e com outros enxames de diques de idade similar do Supercontinente Columbia, inferências geoquímicas e geodinâmicas importantes para o estudo da evolução do Cráton Amazônico (Scharer et al., 1986; Ahall e Connelly, 1998; Upton et al., 2005; Corrêa da Costa et al., 2009; El Bahat et al., 2013; Söderlund et al., 2013).

\section{CONTEXTO GEOTECTÔNICO E GEOLÓGICO}

A área de estudos está inserida na região leste da PAAF (Dardenne e Schobbenhaus, 2001) (Figura 1), na porção centro-sul do Cráton Amazônico, compreendendo uma estreita faixa com extensão de aproximadamente $500 \mathrm{~km}$ na direção WNW-ESE, limitada a norte pelo gráben do Cachimbo e a sul pelo gráben do Caiabis (Dardenne e Schobbenhaus, 2001; Moreton e Martins, 2005; Silva e Abram, 2008). Composta de suítes plutonovulcânicas de idades que variam de 2,04 a $1,75 \mathrm{Ga}$, está inserida nas províncias Ventuari-Tapajós (1,95 a $1,8 \mathrm{Ga}$ ), em sua porção nordeste, e Rio Negro-Juruena (1,8 a $1,55 \mathrm{Ga}$ ), em sua porção sudoeste (Tassinari e Macambira, 1999, 2004) (Figura 1). Cordani e Teixeira (2007) atribuem a essas províncias intervalos de idade pouco diversos, ou seja, de 2,00 a 1,80 Ga para Ventuari-Tapajós e de 1,78 a 1,60 Ga para Rio Negro-Juruena.

Segundo modelo de Santos et al. (2000), a PAAF está inserida nas províncias Tapajós-Parima (2,03 a 1,88 Ga), em sua porção leste, e Rondônia-Juruena (1,82 a 1,54 Ga), em sua porção oeste. Embora os limites das províncias geocronológicas sejam um tema em constante discussão, os autores supracitados sugerem para a evolução do Cráton Amazônico uma sucessiva acreção de arcos magmáticos orientados segundo NW-SE em um terreno de idade Arqueana, estabilizados em 1,0 Ga (Teixeira et al., 1989; Tassinari e Macambira, 1999, 2004; Santos et al., 2000; Cordani e Teixeira, 2007).

Considerando-se dados estruturais dos litotipos presentes na PAAF, dois domínios geológicos distintos foram definidos: domínio deformado ou dúctil e domínio indeformado ou rúptil (Souza et al., 2005; Silva e Abram, 2008; Santos et al., 2019). O domínio indeformado é composto de pequenos registros de rochas metamórficas constituindo associação gnaisse-migmatítica com idade de 2,84 a $2,79 \mathrm{Ga}$, que representa o embasamento dos litotipos da região; extenso magmatismo calcioalcalino, que varia de 1,98 a $1,78 \mathrm{Ga}$, e extenso plutonovulcanismo, composto de rochas de afinidade calcioalcalina do tipo A com idades entre 1,78 e 1,75 Ga. Já o domínio deformado é composto de granitoides com afinidade geoquímica calcioalcalina, sin-tectônicos marcados por extensas zonas de cisalhamento e foliações penetrativas com idades que variam entre 1,79 e 1,74 Ga.

O embasamento do domínio indeformado ou rúptil é constituído de rochas gnáissicas pertencentes ao complexo metamórfico que ocorre de forma restrita na PAAF. Paes de Barros (2007) descreve o Gnaisse Gavião como tonalito gnaisse apresentando idade $\mathrm{Pb}-\mathrm{Pb}$ em seu paleossoma de 2816 $\pm 4 \mathrm{Ma}$ - dessa forma, englobando-o ao Complexo Xingu.

Englobados como Complexo Cuiú-Cuiú, os gnaisses graníticos a tonalíticos, xistos e formações ferríferas bandadas (1992 \pm Ma; Souza et al., 2005), bem como o Gnaisse Alto Alegre (1984 \pm 7 Ma; Paes de Barros, 2007) e o Gnaisse 

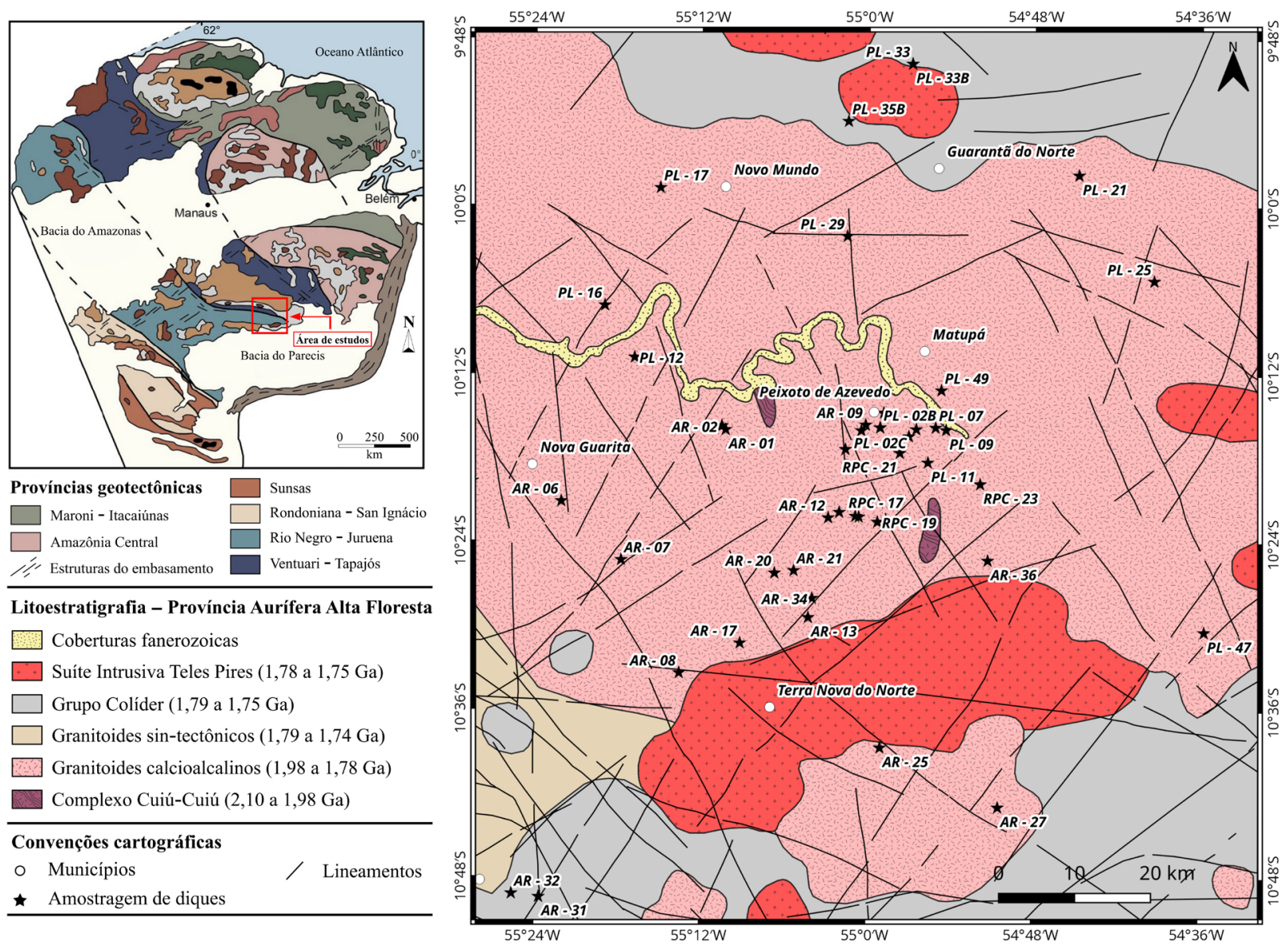

Fonte: modificado de Lacerda-Filho et al. (2004) e Tassinari e Macambira (2004).

Figura 1. Mapa geotectônico e geológico da região leste da Província Aurífera Alta Floresta.

Nova Guarita (1980 \pm 8 Ma; Assis, 2015), ocorrem na porção indeformada da região leste da PAAF. Desse modo, Assis (2015) associa tais litotipos com o extenso magmatismo calcioalcalino isotrópico da Suíte Intrusiva Nhandu, denominando esse evento magmático de Arco Magmático Cuiú-Cuiú. As unidades da Suíte Intrusiva Nhandu correspondem aos litotipos Granito Novo Mundo (U-Pb 1970 a 1964 Ma; Paes de Barros, 2007), Suíte Pé Quente (U-Pb $1979 \pm 31$ Ma; Miguel Jr., 2011), Granito Aragão (U-Pb $1931 \pm 12$ Ma; Miguel Jr., 2011; 1964 a 1967 Ma; Dezula et al., 2018), bem como as rochas do garimpo Trairão (U-Pb $1969 \pm 7$ Ma e $1954 \pm 4$ Ma; Rocha, 2016).

O segundo evento magmático na região leste da PAAF compreende as rochas com afinidade calcioalcalina Granodiorito X1 (1904 \pm 4 Ma; Miguel Jr., 2011; Assis, 2015), Tonalito Pé Quente (1901 \pm 7 Ma; Assis, 2015; Miguel Jr., 2011), Suíte Intrusiva Matupá ( $1878 \pm 7$ Ma a $1863 \pm 4$ Ma; Moura, 1998; Moura et al., 2006; Assis, 2015; Silva et al., 2014; Rocha, 2016), Granodiorito União (1853 \pm 23 Ma;
Assis, 2015; Miguel Jr., 2011), Granito Peixoto (1792 \pm 2 Ma e $1781 \pm 10$ Ma; Paes de Barros, 2007; Silva et al., 2014) e as rochas vulcânicas do Grupo Colíder (1795 a 1751 Ma; Pimentel e Botelho, 2001; Pinho, 2002; Pinho et al., 2003; Silva e Abram, 2008; Santos et al., 2019). Tal associação litológica caracteriza-se como Arco Magmático Juruena, cujas características são de arco maduro e intervalo aproximado de 1904 a 1781 Ma, justaposto ao Arco Magmático Cuiú-Cuiú (Lacerda Filho et al., 2004; Souza et al., 2005; Silva e Abram, 2008; Duarte et al., 2012, 2016).

As unidades pertencentes ao Arco Magmático Cuiú-Cuiú e ao Arco Magmático Juruena são intrudidas pela Suíte Intrusiva Teles Pires, anorogênica com afinidade geoquímica típica de rochas do tipo A e idades que variam de 1782 a $1757 \mathrm{Ma}$. Esse evento magmático estaria relacionado ao estágio pós-orogênico do Arco Magmático Juruena (Duarte et al., 2012; Assis, 2015; Assis et al., 2017). Mesmo englobado como Suíte Intrusiva Teles Pires, algumas denominações são usadas na tentativa de caracterizar as rochas 
pós-orogênicas do tipo A, como Granito Terra Nova, Pórfiro X1 e Pórfiro União do Norte (Pinho et al., 2001; Moreton e Martins, 2005; Silva e Abram, 2008; Miguel Jr., 2011; Prado et al., 2013; Assis, 2015).

Cortando as unidades descritas anteriormente ocorrem os diques máficos denominados "Diques Básicos" por Moura (1998). Trata-se de diques de diabásio porfirítico na região de Serrinha, próxima à cidade de Matupá, classificados quimicamente como basaltos de médio potássio, subalcalinos. A norte da cidade de Colíder, Moreton e Martins (2005) cartografaram gabros de cor cinza a verde, predominantemente sulfetados e com estrutura maciça. Ocorrência de diques máficos de composição basáltica a andesítica também é descrita e relacionada à Suíte Intrusiva Flor da Serra (Lacerda Filho et al., 2004; Moreton e Martins, 2005; Silva e Abram, 2008). Silva et al. (1980) obtiveram idade K-Ar de $1416 \pm$ $14 \mathrm{Ma}$, concordante com a idade Ar-Ar de $1418 \pm 3,5 \mathrm{Ma}$ obtida por Bispo-Santos et al. (2012) nas proximidades da cidade de Nova Guarita. Tendo-se como foco os enxames cuja estratigrafia é idêntica à da região estudada, ou seja, os gabros do Complexo Colorado (1352 $\pm 4 \mathrm{Ma}$; Teixeira et al., 2006), o enxame Nova Lacerda (1387 \pm 17 Ma; Corrêa da Costa et al., 2009; Girardi et al., 2012; Teixeira et al., $2016)$, os diques do enxame Nova Guarita (1419 $\pm 3 \mathrm{Ma}$; Bispo-Santos et al., 2012) e os diques que cortam os arenitos da Formação Dardanelos (1416 \pm 14 Ma; Silva et al., 1980), sugere-se correlação temporal entre eles. Os diques da região de Peixoto de Azevedo e de Nova Guarita pertenceriam, portanto, ao mesmo enxame, admitindo-se a idade de 1419 Ma (Bispo-Santos et al., 2012).

\section{MATERIAIS E MÉTODOS}

Para o reconhecimento dos diques em campo foram utilizados campo magnético anômalo e filtro de primeira derivada vertical a partir dos dados brutos de levantamentos geofísicos referentes ao Projeto Aerogeofísico Norte do Mato Grosso-1121 (Figuras 2A e 2B).

A coleta de dados resultou na amostragem de 77 diques máficos, dos quais, com base nas análises petrográficas em seções delgadas preparadas no laboratório da Faculdade de Geociências da Universidade Federal de Mato Grosso (FAGEO/UFMT), os dados geoquímicos foram obtidos a partir de 23 amostras consideradas mais representativas do enxame de diques estudado. As amostras selecionadas foram previamente reduzidas em britador e moinho de panelas no laboratório de preparação de amostras da FAGEO/UFMT. Para as análises geoquímicas, as amostras foram encaminhadas para o laboratório de Fluorescência de Raio X e de Química e ICP-MS (Inductively Coupled PlasmaMass Spectrometry) do Departamento de Mineralogia e Geotectônica do Instituto de Geociências da Universidade de São Paulo (GMG/IGc/USP), onde se determinou a composição química de rocha total por meio de fluorescência de raios X para elementos maiores segundo metodologia de Mori et al. (1999). A determinação dos teores de elementos traços incluindo terras raras foi obtida de oito amostras utilizando ICP-MS, de acordo com o procedimento descrito por Navarro et al. (2008). Os erros analíticos obtidos nas amostras estão dentro dos limites fornecidos pelo laboratório. Os diagramas geoquímicos foram tratados utilizando-se o software GCDKit versão 5.0 (Janousek et al., 2003).

\section{GEOLOGIA LOCAL E PETROGRAFIA}

Os diques máficos têm como encaixantes rochas paleoproterozoicas representadas pelo Gnaisse Nova Guarita, Granodiorito X1, Suíte Intrusiva Nhandu, Suíte Intrusiva Matupá, Granodiorito União, Granito Peixoto, vulcânicas do Grupo Colíder e Suíte Intrusiva Teles Pires, unidades pertencentes aos arcos magmáticos Cuiú-Cuiú e Juruena (Figura 1).

Os diques apresentam maior concentração na região próxima à cidade de Peixoto de Azevedo (Figura 1). O enxame de diques máficos ocorre como intrusões verticais a subverticais, geralmente formando cristas em morrotes, como pequenos lajedos e cortes de estradas. Apresenta contatos abruptos com as rochas encaixantes. Tais diques apresentam direções próximas aos lineamentos encontrados na área de estudos (Figura 2C), variando de N25E a N80E com valor médio de N60E, bem como N50W a N80W com valor médio de N70W (Figura 2C), apresentando espessuras que variam de 5 a $40 \mathrm{~m}$ e extensões que variam de aproximadamente 4 a $32 \mathrm{~km}$. As medidas estruturais dos diques amostrados em campo mostram-se próximas dos lineamentos regionais interpretados a partir da primeira derivada vertical do campo magnético total (Figuras 2C e 2D).

Os diabásios são maciços, holocristalinos com granulação fina a média. Apresentam texturas fanerítica, subofítica a ofítica (Figuras 3A e 3B), intergranular e porfirítica com fenocristais de plagioclásio imersos em uma matriz mais fina. São formados predominantemente por plagioclásio (andesina a labradorita) e augita, ocorrendo subordinadamente enstatita e biotita. A augita mostra, por vezes, bordas alteradas em actinolita e clorita. A olivina ocorre somente em duas amostras (AR-07 e PL-16) em quantidades muito pequenas e com bordas alteradas para iddingsita. A biotita, por vezes, forma estruturas radiais. Zircão, apatita e titanita são minerais acessórios. Em várias amostras porfiríticas os fenocristais de plagioclásio, quando menores, formam estruturas radiais imersas em uma matriz de minerais máficos.

Alguns minerais secundários são considerados produtos de um processo hidrotermal associado aos estágios finais da cristalização dessas rochas, sendo compostos de sericita, 


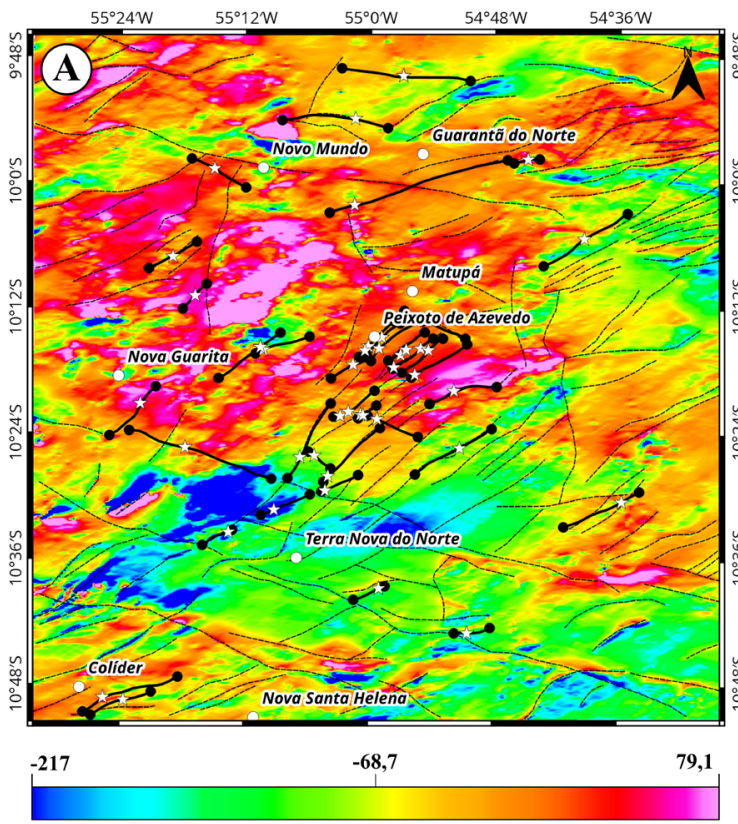

Campo Magnético Anômalo (nT)

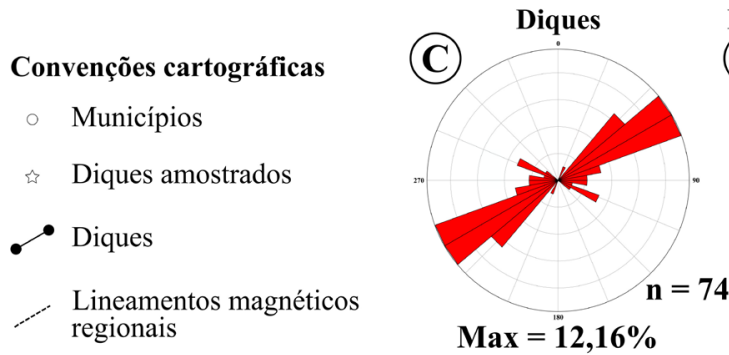

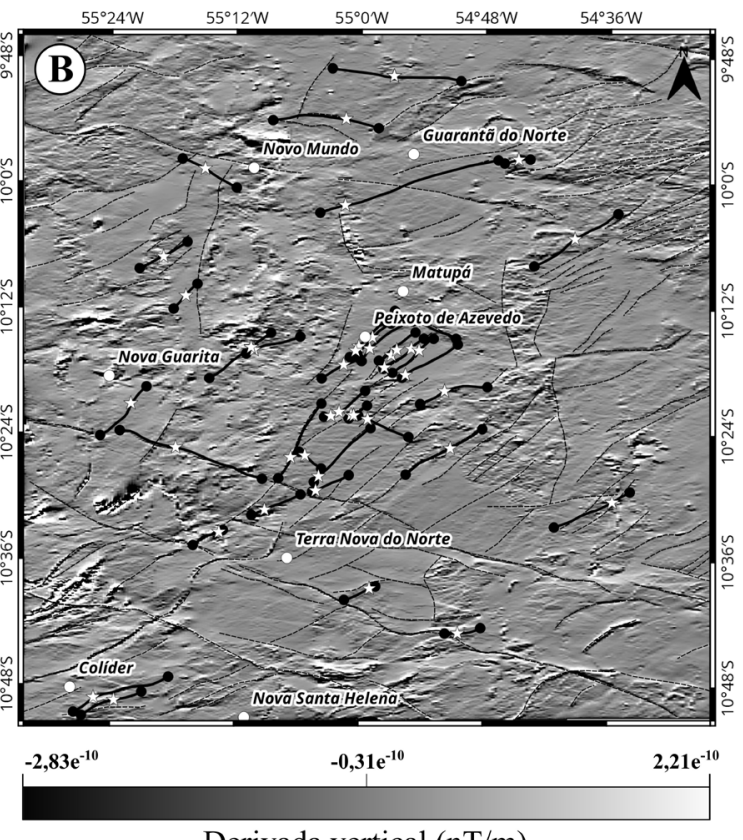

Derivada vertical $(\mathrm{nT} / \mathrm{m})$

Lineamentos magnéticos

(D)

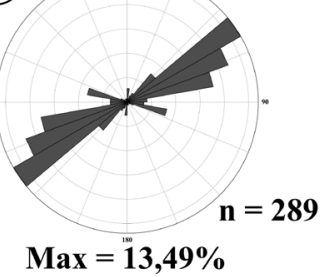

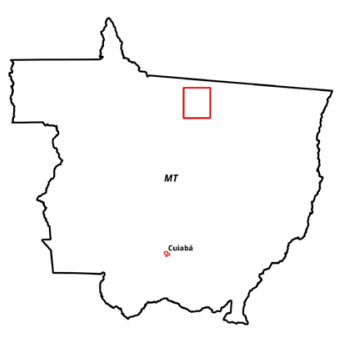

Figura 2. (A) Mapa do Campo Magnético Anômalo; (B) $1^{\text {a }}$ derivada vertical; (C) atitudes dos diques máficos; e (D) lineamentos magnéticos regionais.
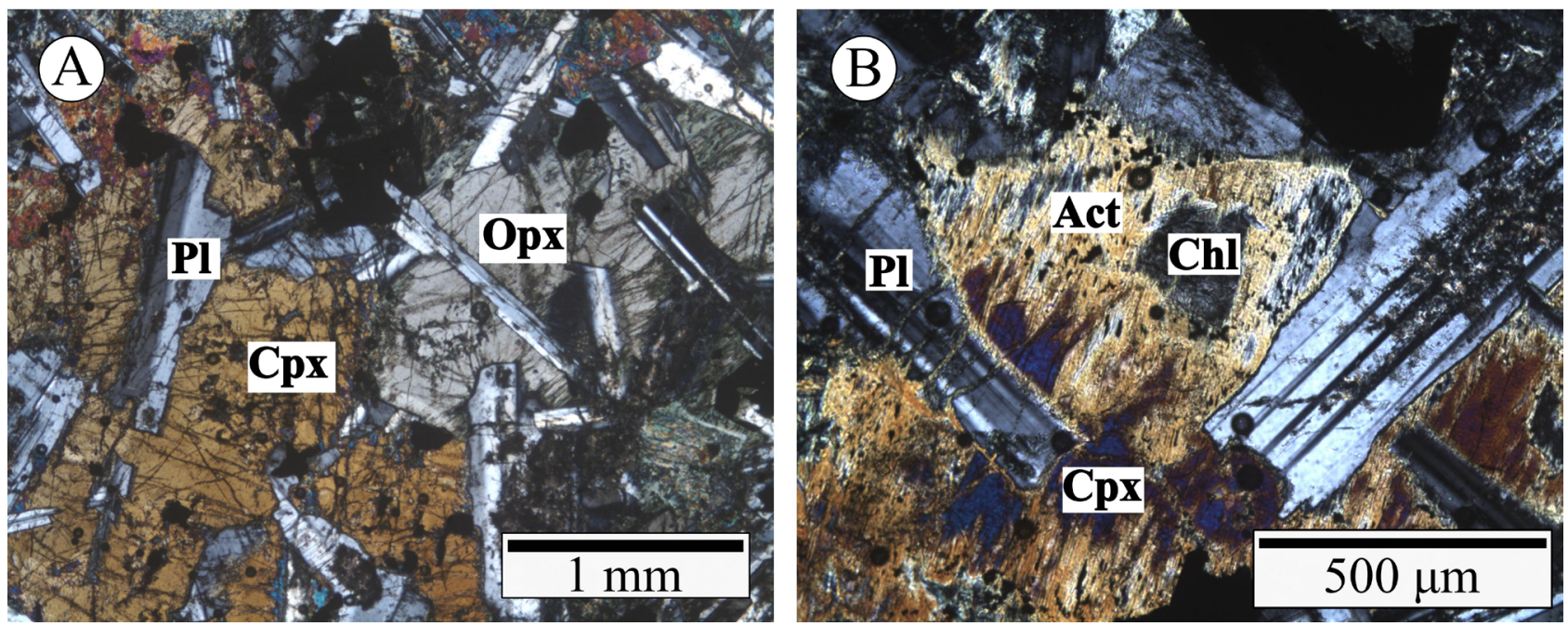

Act: actinolita; Chl: clorita; Cpx: clinopiroxênio; Opx: ortopiroxênio; Pl: plagioclásio.

Figura 3. Fotomicrografia de luz transmitida dos diques de diabásio: (A) PL-49: cristais de plagioclásio imersos em augita e enstatita, caracterizando textura ofítica; (B) PL-25: detalhe de augita alterada para actinolita e clorita, bem como a imersão parcial do plagioclásio, evidenciando textura subofítica. 
actinolita, hornblenda, clorita, epídoto, iddingsita e argilominerais. Veios de quartzo com sulfetos do tipo pirita e calcopirita são também resultados desse processo. Os minerais opacos são representados por magnetita, hematita, ilmenita e pirita, sendo hematita e ilmenita os mais representativos.

\section{GEOQUÍMICA}

\section{Classificação geoquímica}

A partir do tratamento dos dados geoquímicos apresentados na Tabela 1, o diagrama de série magmática AFM $\left(\mathrm{Na}_{2} \mathrm{O}+\mathrm{K}_{2} \mathrm{O} ; \mathrm{FeO} ; \mathrm{MgO}\right)$ de Irvine e Baragar (1971) mostra para os diabásios uma afinidade toleítica com predominante enriquecimento em $\mathrm{FeO}$ (Figura 4A). Segundo o diagrama de classificação de TAS (total de álcalis vs. sílica) de Le Bas et al. (1986), trata-se de basaltos, à exceção de uma amostra classificada como traquibasalto (AR-27) e duas como basaltos andesíticos (PL-2B e AR09) (Figura 4B).

\section{Elementos maiores, menores e traços}

Os valores de $\mathrm{TiO}_{2}$ variam de 0,57 a 2,56\%; os de $\mathrm{MgO}$, de 4,00 a $8,73 \%$; e os de $\mathrm{FeO}$, de 9,34 a 13,55\%. Assumindo a razão de $\mathrm{Fe}_{2} \mathrm{O}_{3} / \mathrm{FeO}=0,15$, os diques de diabásio apresentam valores de $\mathrm{Mg} \#\left[\mathrm{Mg} \#=\mathrm{Mg}^{2+} /\left(\mathrm{Mg}^{2+}+\mathrm{Fe}^{2+}\right)\right]$ entre $0,34 \mathrm{e}$ 0,62 , indicando assim composição de magmas basálticos evoluídos, uma vez que valores de Mg\# de magmas basálticos primários derivados de rochas peridotíticas variam entre 0,72 e 0,80\% (Jaques e Green, 1979, 1980; Takahashi e Kushiro, 1983; Bossi et al., 1993; Kuyumjian, 1998; Kushiro, 2001).

No presente estudo, o diagrama de razões elementares de Pearce (1968; Wang et al., 2006) evidencia a importância do clinopiroxênio no controle do processo (Figura 5A). Nos diagramas de variação, com a diminuição dos valores de $\mathrm{Mg} \#$, diminuem os teores de $\mathrm{CaO}, \mathrm{Al}_{2} \mathrm{O}_{3}$, $\mathrm{Ni}$ e $\mathrm{Cr}$, e aumentam os teores de FeOt, $\mathrm{TiO}_{2}, \mathrm{MnO}, \mathrm{Na}_{2} \mathrm{O}, \mathrm{K}_{2} \mathrm{O}$, $\mathrm{Zr}, \mathrm{Ba}, \mathrm{Ce}, \mathrm{Y}, \mathrm{La}$ e $\mathrm{Nb} . \mathrm{SiO}_{2}, \mathrm{~K}_{2} \mathrm{O}$ e $\mathrm{Rb}$ exibem dispersão (Figuras 6 e 7). Tal comportamento, comum em basaltos toleíticos, é denominado por vários autores como produto de fracionamento tipo gabro, em que olivina, piroxênios e plagioclásios cálcicos podem atuar em proporções variadas.

$\mathrm{O}$ uso de elementos traços sob a forma de diagramas e razões é de grande utilidade na identificação das características da fonte mantélica, especialmente quando empregados pares de elementos altamente incompatíveis cujos coeficientes de partição são similares, ou quando os coeficientes de partição são muito menores que a fração do material fundido. Em ambos os casos, as razões entre eles não mudam durante a cristalização fracionada e mudam muito pouco durante a fusão. Portanto, é aconselhável o uso de razões de elementos com coeficiente de partição semelhantes, como
$\mathrm{Ba} / \mathrm{La}, \mathrm{Ba} / \mathrm{Nb}$ e La/Nb. Além desses elementos, outros com coeficientes de partição mais distantes são também importantes para estudos petrogenéticos, tais como $\mathrm{La} / \mathrm{Sm}, \mathrm{La} / \mathrm{Yb}$, $\mathrm{Ti} / \mathrm{Zr}, \mathrm{Ti} / \mathrm{Y}, \mathrm{Zr} / \mathrm{Y}$ e Ce/Y.

O diagrama de Pearce (2008), Th/Yb versus $\mathrm{Nb} / \mathrm{Yb}$, propõe investigar a relação de basaltos e seus possíveis reservatórios mantélicos parentais N-MORB, E-MORB e OIB, assim como inferir a respeito de processos de contaminação dessas fontes mantélicas. No presente caso, observa-se que apenas uma amostra se situa dentro do campo formado pelo alinhamento N-MORB, E-MORB e OIB, enquanto as demais tendem a um alinhamento paralelo - algo disperso acima desse campo (Figura 5B).

No diagrama multielementar, os diques de Peixoto de Azevedo-Nova Guarita, normalizados segundo o manto primitivo de McDonough e Sun (1995), apresentam picos positivos de elementos litófilos de grande raio iônico (LILE: $\mathrm{Rb}, \mathrm{Ba}$ e $\mathrm{K}$ ), e de terras raras leves (LREE: La e Ce), bem como anomalias negativas para os elementos de alto potencial iônico (HFSE: Nb e Zr). À exceção de uma amostra Sr, exibem picos positivos, provavelmente relacionados ao fracionamento de plagioclásio (Figura 8A). Os demais elementos apresentam padrão planar, com exceção do pico positivo de Ti em uma amostra. Considerando os valores de todas as amostras, a somatória dos elementos terras raras ( $\mathrm{R} R E E$ ) varia de 49,02 a 292,03 ppm e as razões LREE/HREE, de 4,84 a 11,66. Os diques de diabásio, quando normalizados segundo o condrito de Boynton (1984), apontam significativo enriquecimento de LREE em relação aos HREE (Figura 8B).

Os diagramas multielementar e de terras raras dos diques de Peixoto de Azevedo-Nova Guarita apresentam semelhanças com os de Nova Lacerda, com o global subducting sediment composition (GLOSS) — que representa uma média estimada de sedimentos subductados - , com os diques datados em 1,8 Ga de Carajás e com as rochas máficas da Suíte Vespor $(1,77$ a $1,76 \mathrm{Ga})$, cujas fontes, assim como a do enxame de Nova Lacerda, foram enriquecidas por material sedimentar subductado (Corrêa da Costa et al., 2009; Scandolara et al., 2014; Giovanardi et al., 2019). As Figuras 9A e 9B mostram diagramas dos valores médios dessas ocorrências, cuja comparação é também retratada pelos valores médios de razões dos incompatíveis (Tabela 2). Os diques de Peixoto de Azevedo-Nova Guarita caracterizam-se pelos altos valores de razões LILE/HFSE e LREE/HFSE (representadas por $\mathrm{Ba} / \mathrm{Nb}$ e La/Nb, respectivamente) e de razões LREE/HREE e LREE/MREE (representadas, respectivamente, por $\mathrm{La} / \mathrm{Yb}$ e $\mathrm{La} / \mathrm{Sm}$ ). Grande parte das razões do enxame em estudo assemelha-se às do GLOSS $(\mathrm{Zr} / \mathrm{Y}, \mathrm{Ba} / \mathrm{Nb}, \mathrm{La} / \mathrm{Nb}$ e $\mathrm{Ba} / \mathrm{La})$, sendo a maior divergência nas razões relacionadas a Ti, em razão de seu baixo teor em sedimentos. A grande influência dos sedimentos na contaminação da fonte mantélica foi responsável pela maior parte das razões de elementos incompatíveis com as dos diques máficos de 1882 Ma de Carajás (Giovanardi 


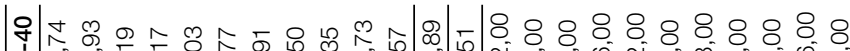

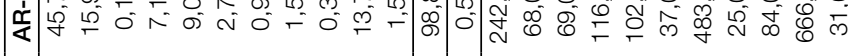

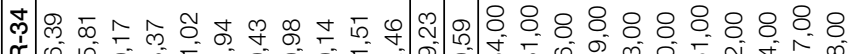

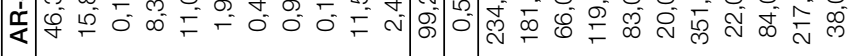

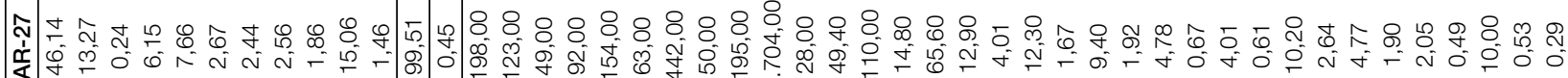

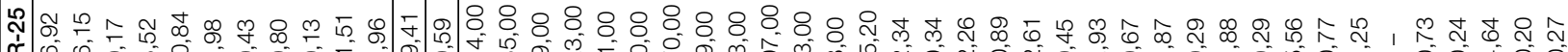

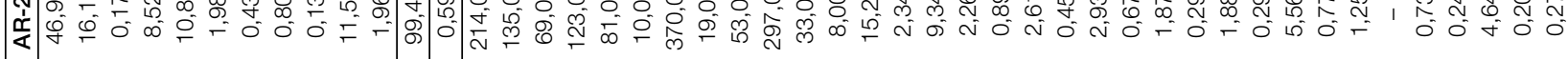

$\overline{4}$

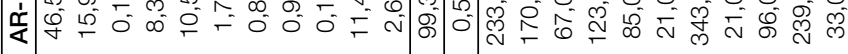

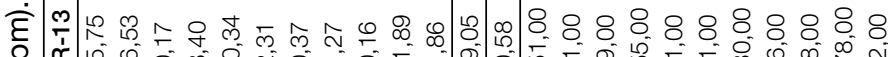

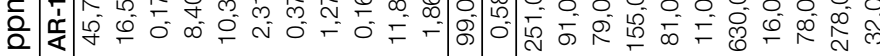

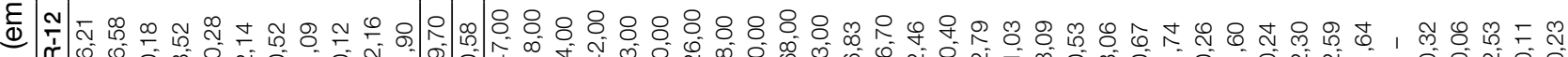
m ๘ कृ

Ф)

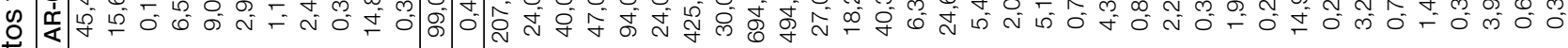

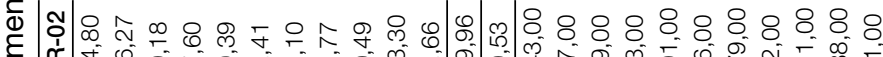

$\frac{0}{\omega}$

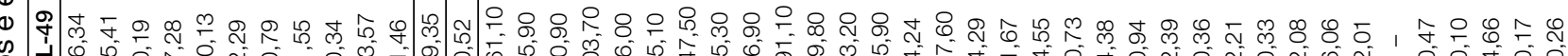

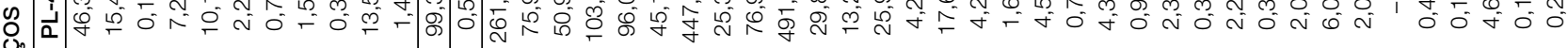

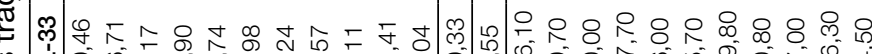

ô

d

$\frac{0}{0}$

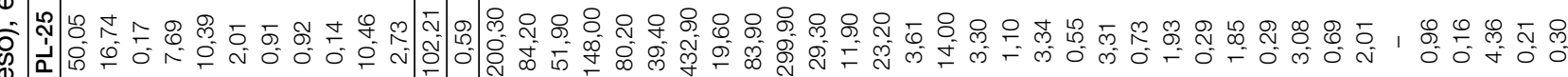

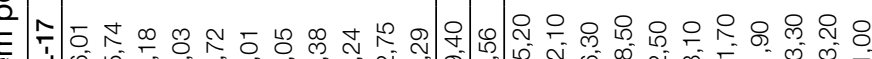

d)

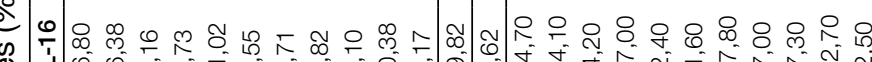

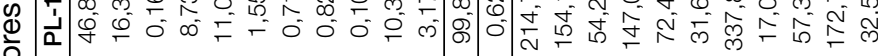

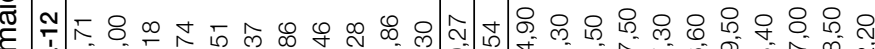

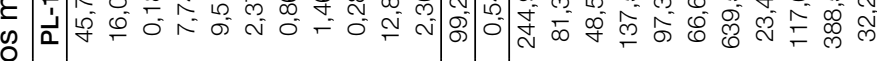

可

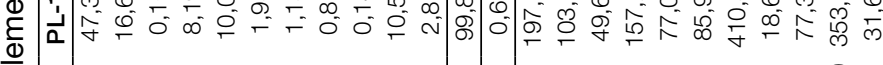

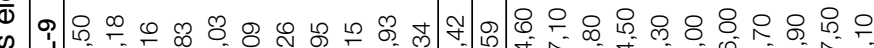

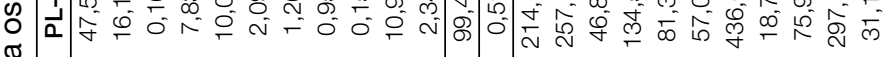

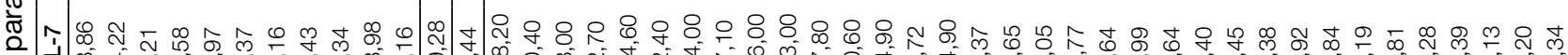
D)

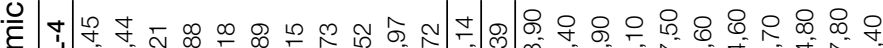

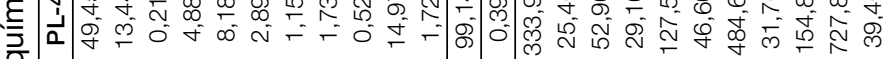

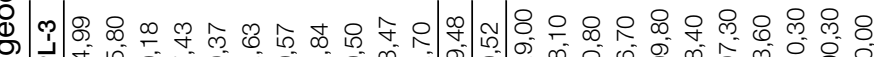

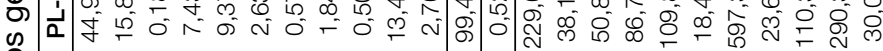

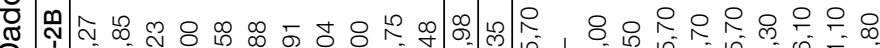

D.

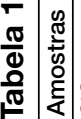

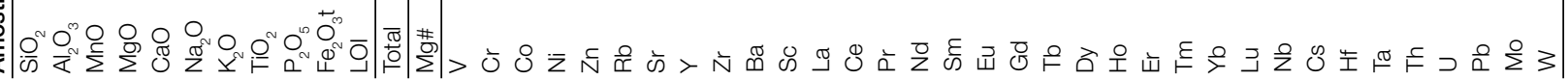



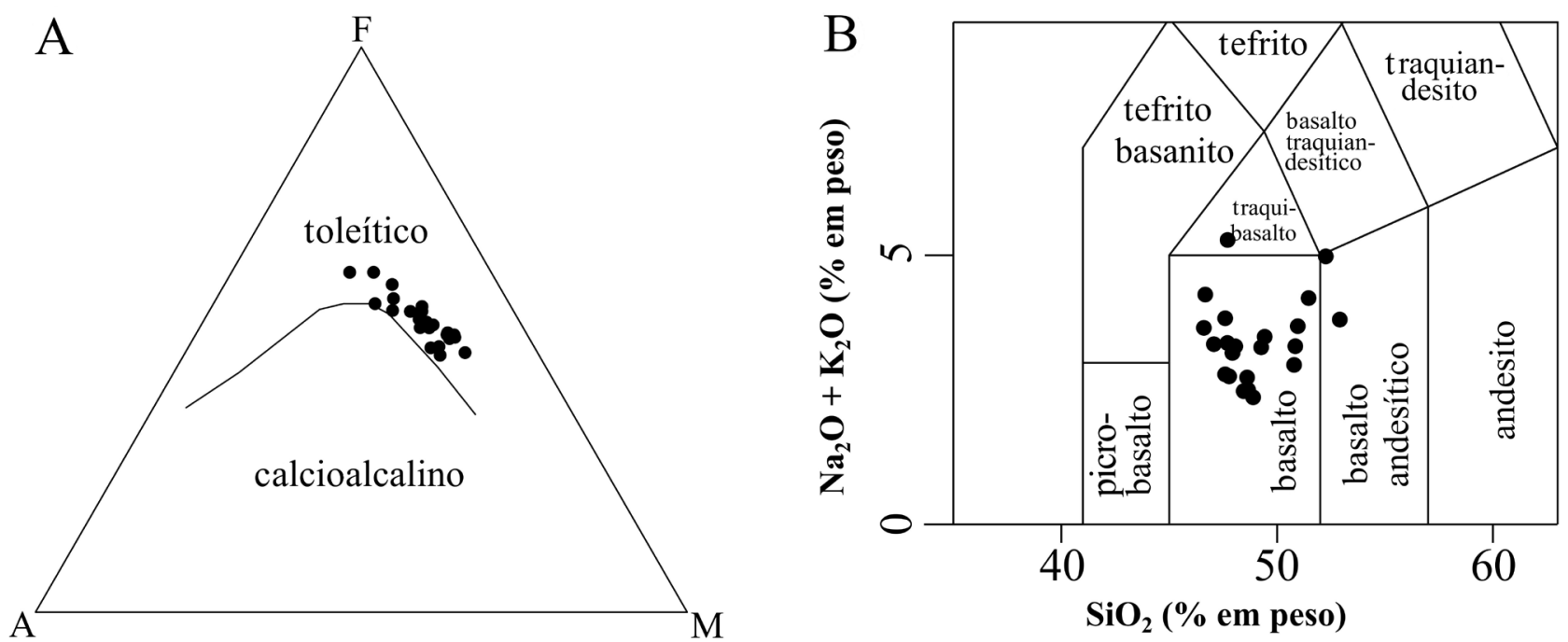

Figura 4. (A) Diagrama $\mathrm{AFM}\left(\mathrm{Na}_{2} \mathrm{O}+\mathrm{K}_{2} \mathrm{O} ; \mathrm{FeO}\right.$; MgO) segundo Irvine e Baragar (1971); (B) diagrama TAS (total de álcalis vs. sílica) segundo Le Bas et al. (1986).

$\mathbf{A}$

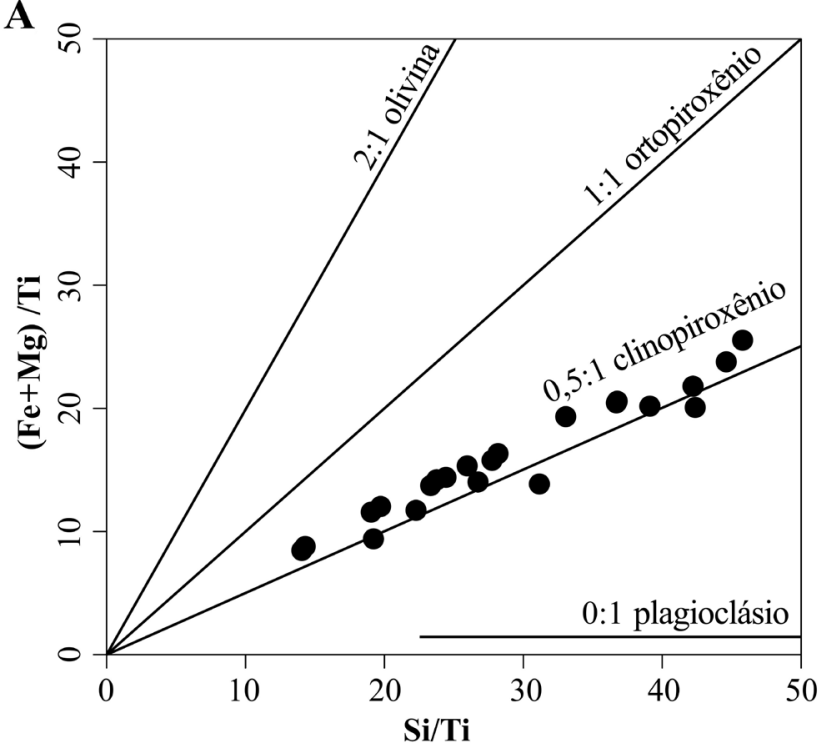

B

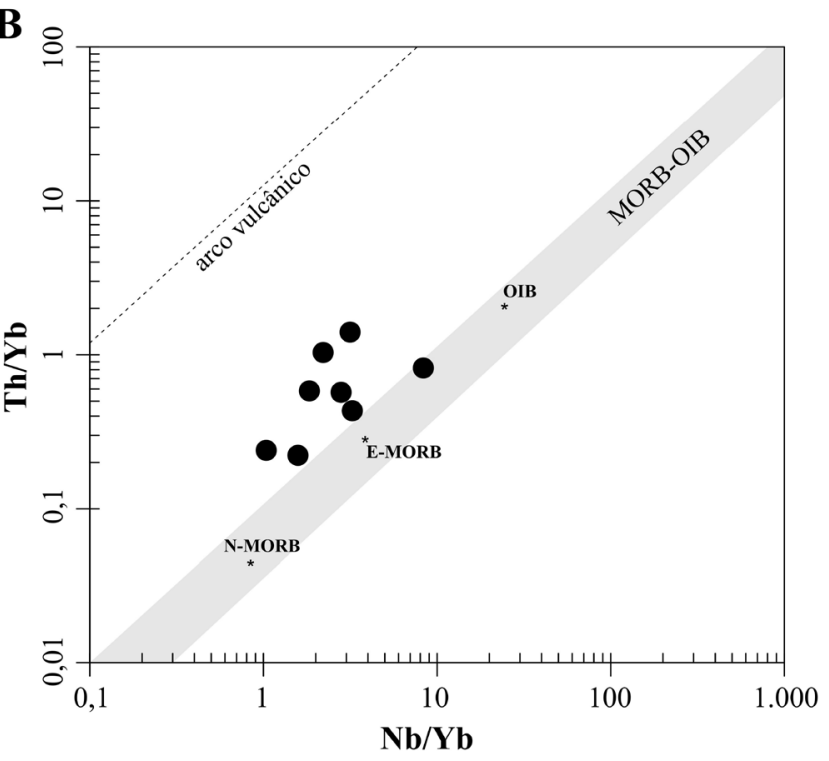

Figura 5. (A) Diagrama de razões elementares para rochas máficas de Pearce (1968; Wang et al., 2006); (B) diagrama discriminante $\mathrm{Th} / \mathrm{Yb}$ versus $\mathrm{Nb} / \mathrm{Yb}$ segundo Pearce (2008).

et al., 2019), em que, à exceção das razões de Ti/Zr, Ti/Y e $\mathrm{Zr} / \mathrm{Nd}$, mostram valores muito próximos. Em relação a Nova Lacerda, Ti/Zr e Ba/La mostram-se muito semelhantes, porém as razões envolvendo $\mathrm{Ce}$, La e Ba como numeradores e elementos HSFE ( $\mathrm{Nb}$ e $\mathrm{Yb}$ ), MREE ( $\mathrm{Sm}$ ) e HREE ( $\mathrm{Yb}$ ) como denominadores são menores, evidenciando menor contribuição sedimentar no manto progenitor desses diques. Em comparação com as rochas máficas da Suíte Vespor, Nova Lacerda também apresenta valores próximos para as razões, exceto em $\mathrm{Ce} / \mathrm{Y}, \mathrm{Ti} / \mathrm{Zr}$ e Ti/Y. Quando comparado com o
E-MORB Atlântico, ressalta-se a grande semelhança das razões de $\mathrm{Ti}(\mathrm{Ti} / \mathrm{Zr}$ e Ti/Y), além de $\mathrm{Zr} / \mathrm{Y}$.

\section{PETROGÊNESE E O MANTO PARENTAL}

O padrão homogêneo exibido pelas amostras no diagrama multielementar dos diques da Peixoto de Azevedo-Nova Guarita (Figura 8), caracterizado por forte enriquecimento de $\mathrm{Ba}, \mathrm{Rb}, \mathrm{La}$ e Ce em relação a $\mathrm{Nb}$ e de $\mathrm{La}$ em relação a Sm, 

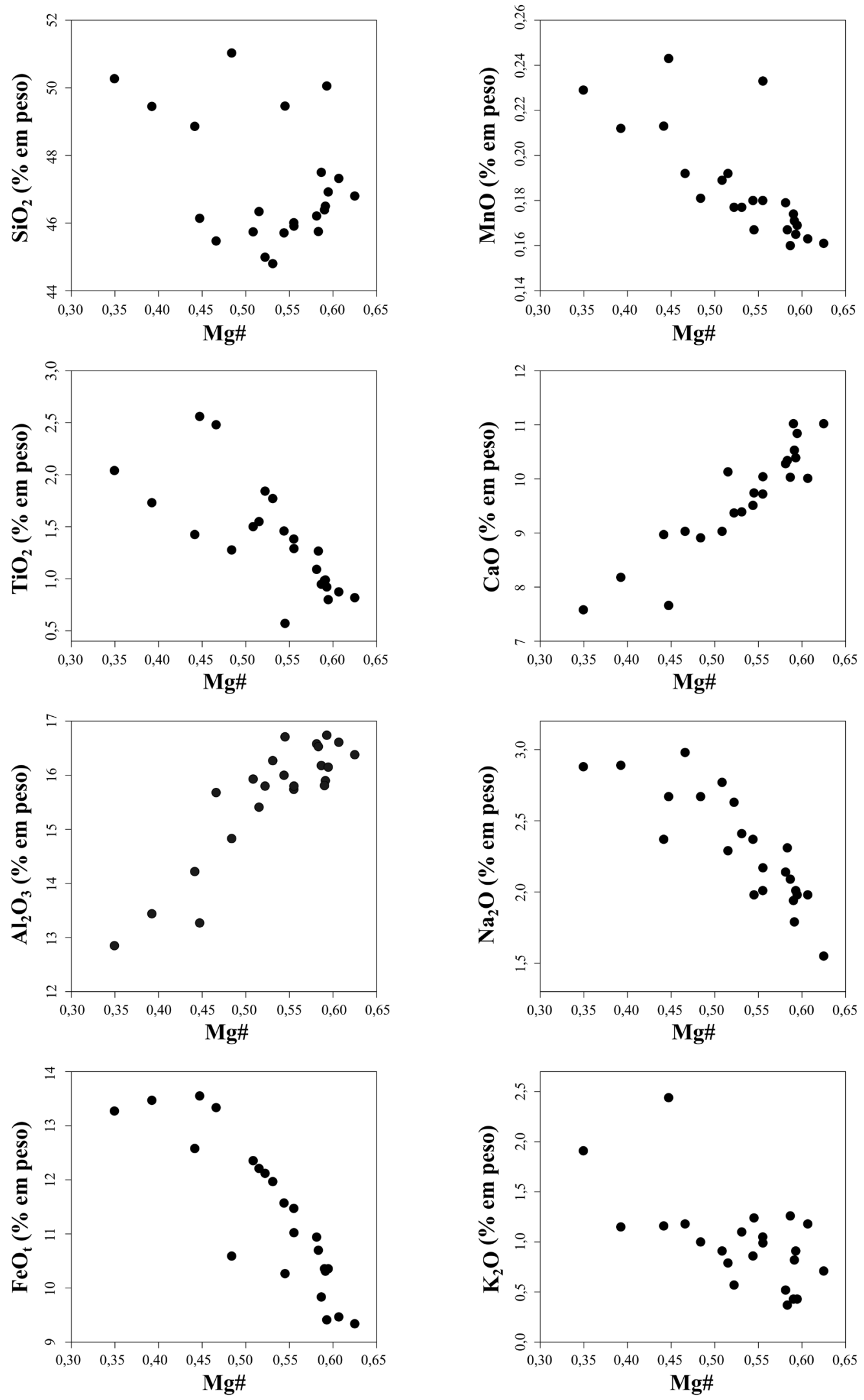

Figura 6. Diagramas de variação para elementos maiores, \% em peso. 

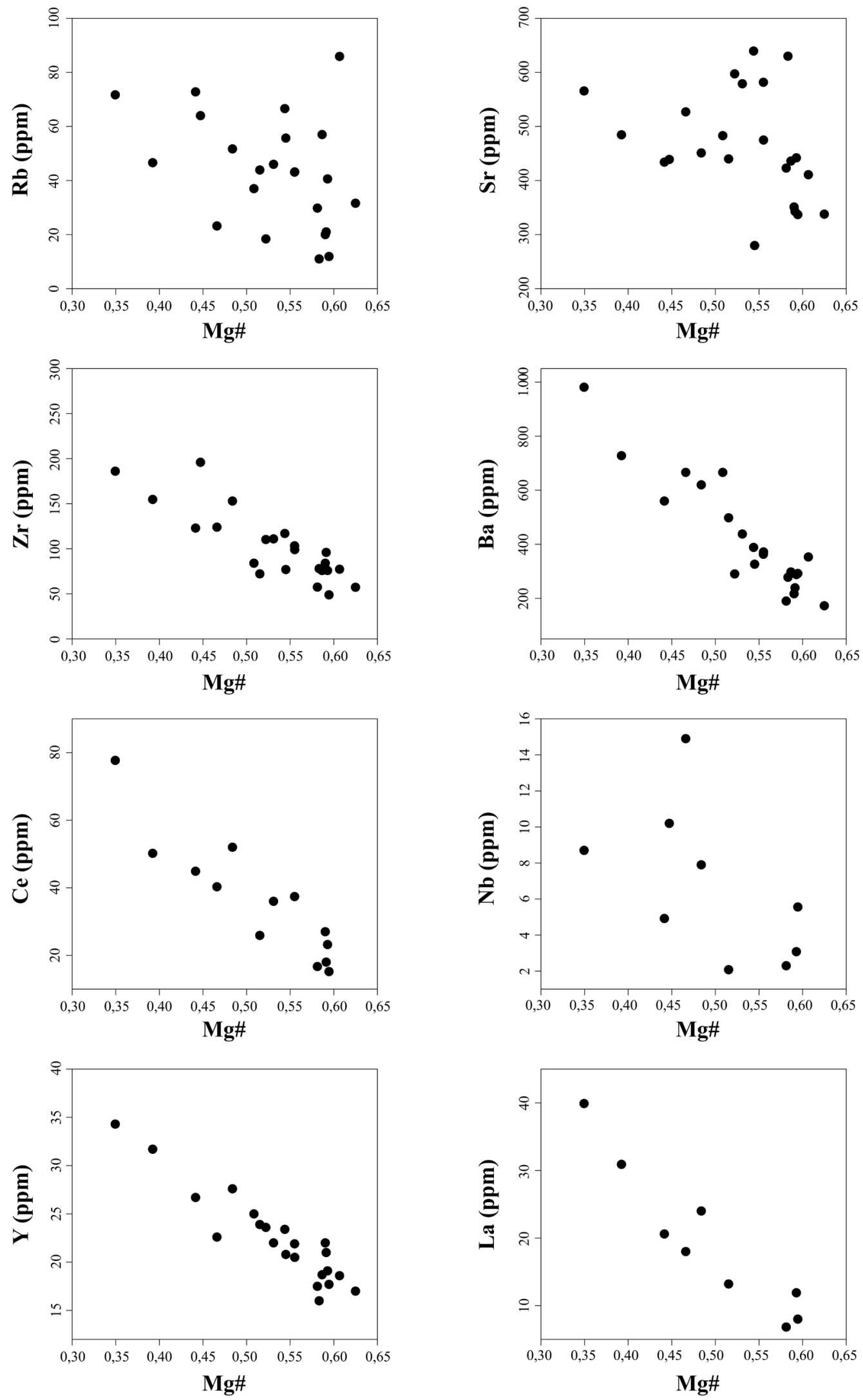

Figura 7. Diagramas de variação para elementos traços, em ppm. 

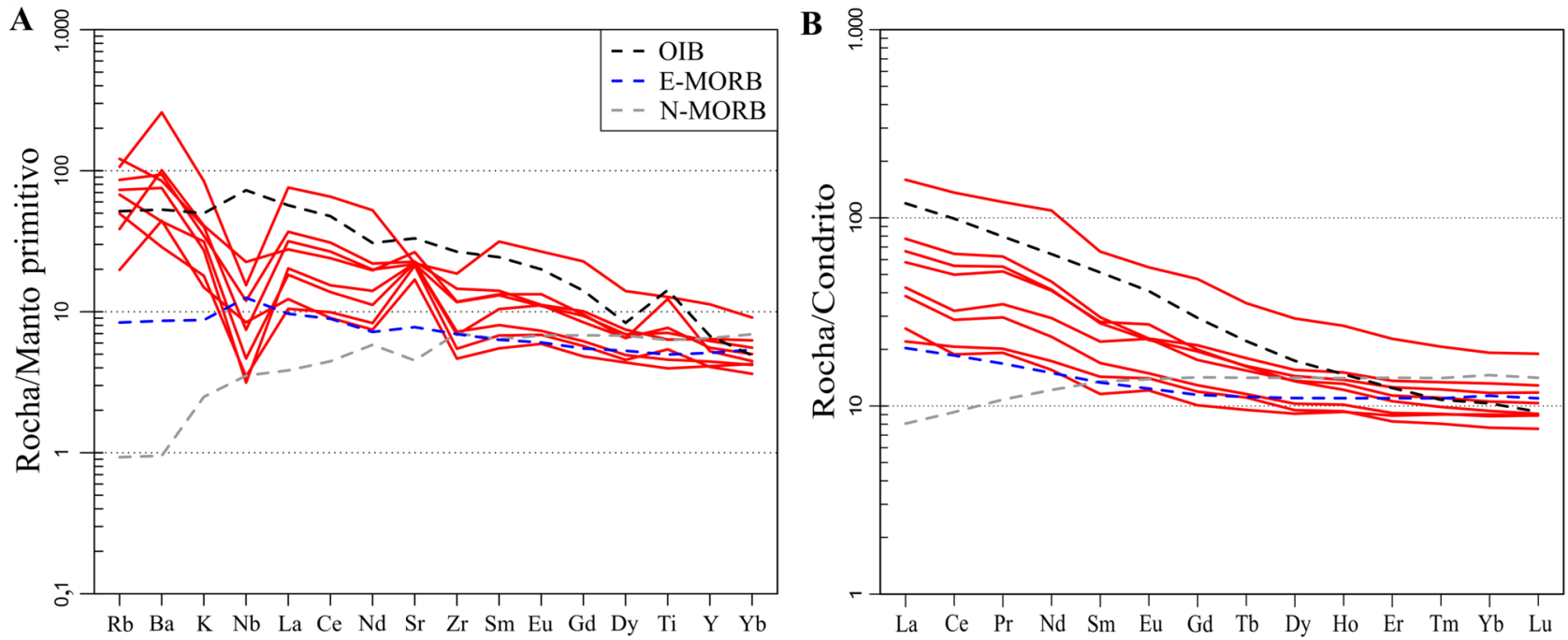

Figura 8. (A) Diagrama multielementos normalizados segundo manto primitivo de McDonough e Sun (1995); (B) diagrama de elementos terras raras normalizados segundo condrito de Boynton (1984). Os valores de OIB, E-MORB e N-MORB de Sun e McDonough (1989) são exibidos para efeitos de comparação.
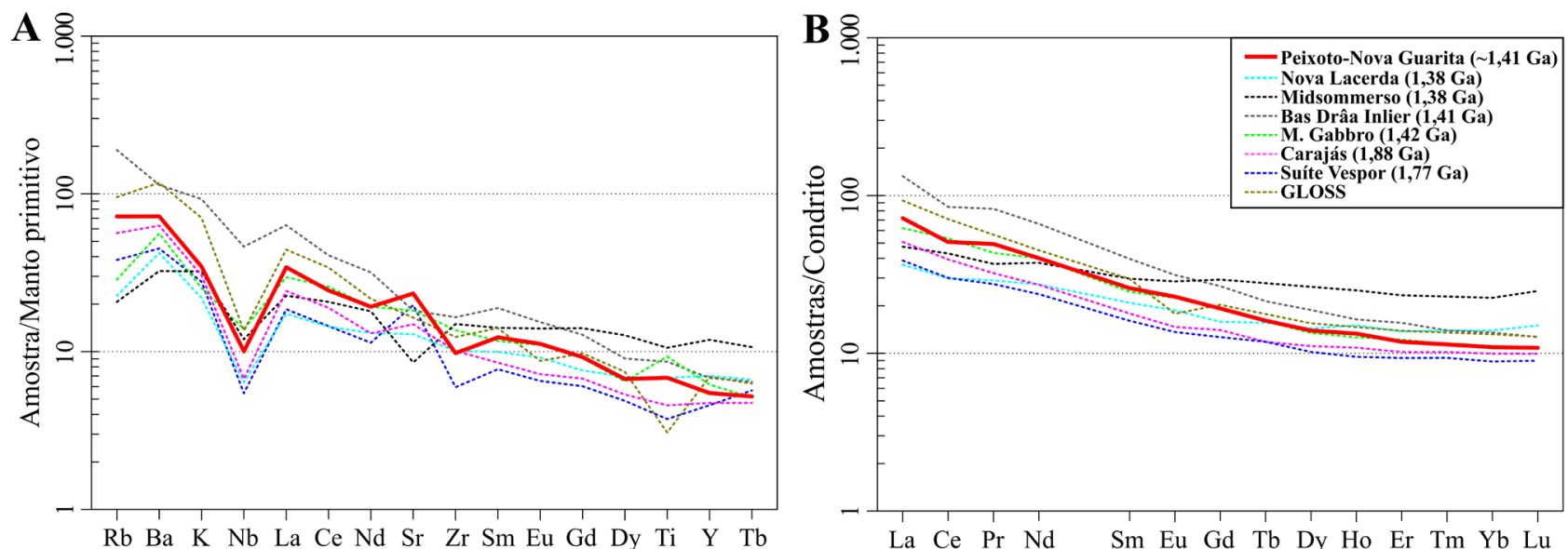

GLOSS: global subducting sediment composition.

Figura 9. (A) Diagrama de médias de elementos incompatíveis normalizados segundo manto primitivo de McDonough e Sun (1995); (B) diagrama de médias para elementos terras raras normalizados segundo condrito de Boynton (1984).

resulta nas altas razões $\mathrm{Ba} / \mathrm{Nb}, \mathrm{La} / \mathrm{Nb}$ e La/Sm (Tabela 2). Tais características são comuns em basaltos intraplaca e de arcos magmáticos e podem resultar ou de assimilação de crosta continental ou em razão de subduç̧ão de crosta oceânica sob o manto sublitosférico. Nesse modelo, fluidos provenientes da crosta oceânica subductada, recoberta por quantidade variável de sedimentos, provocam metassomatismo no manto.

O enriquecimento de elementos LILE e LREE é atribuído aos sedimentos subductados, enquanto a anomalia negativa de $\mathrm{Nb}$ se deve à retenção de rutilo em eclogitos pertencentes à crosta subductada. Pequenas quantidades de rutilo $(\sim 2 \%)$ seriam suficientes para evitar o enriquecimento de $\mathrm{Nb}$ no manto metassomatizado (Brenan et al., 1994, 1995). Outra hipótese atribui a retenção de Ti a outros minerais, como certos anfibólios, ou à baixa solubilidade de Ti em condições hidrotermais (Hofmann, 2007). Esse modelo, utilizado por vários autores (e.g. Cordery et al., 1997; Ayers, 1998; Takahahshi et al., 1998; Rivalenti et al., 1998), foi também adotado no Brasil no enxame de diques Goiás-Crixás (Corrêa da Costa e Girardi, 2005), em vários no SW do Cráton Amazônico (Corrêa da Costa et al., 
Tabela 2. Médias de razões de incompatíveis dos diques de Peixoto-Nova Guarita, Nova Lacerda (Corrêa da Costa et al., 2009; Girardi et al., 2012), Carajás (Giovanardi et al., 2019), Bas Drâa Inlier (El Bahat et al., 2013), Midsommerso (Upton et al., 2005) e Michael Gabbro (Emslie et al., 1997). Valores de N-MORB, E-MORB (McDonough e Sun, 1995), E-MORB Atlântico (Klein, 2004), OIB (Sun e McDonough, 1989) e GLOSS (Plank e Langmuir, 1998).

\begin{tabular}{lcccccccccccc}
\hline & $\begin{array}{c}\text { Peixoto- } \\
\text { Nova } \\
\text { Guarita }\end{array}$ & $\begin{array}{c}\text { Nova } \\
\text { Lacerda }\end{array}$ & Carajás & $\begin{array}{c}\text { Suíte } \\
\text { Vespor }\end{array}$ & GLOSS & $\begin{array}{c}\text { E-MORB } \\
\text { Atlântico }\end{array}$ & E-MORB & N-MORB & OIB & $\begin{array}{c}\text { Michael } \\
\text { Gabbro }\end{array}$ & $\begin{array}{c}\text { Midsommerso } \\
\text { Bas } \\
\text { Drâa } \\
\text { Inlier }\end{array}$ \\
\hline $\mathrm{Rb} / \mathrm{Sr}$ & 0,10 & 0,05 & 0,12 & 0,06 & 0,17 & 0,05 & 0,01 & 0,17 & 0,05 & 0,05 & 0,13 \\
$\mathrm{Zr} / \mathrm{Y}$ & 4,31 & 3,45 & 4,98 & 3,18 & 4,36 & 4,62 & 2,64 & 4,36 & 9,66 & 5,12 & 3,79 & 6,66 \\
$\mathrm{Ce} / \mathrm{Y}$ & 1,50 & 0,80 & 1,51 & 0,16 & 1,92 & 0,90 & 0,26 & 1,92 & 2,75 & 1,65 & 0,99 & 2,62 \\
$\mathrm{Ba} / \mathrm{Nb}$ & 109,50 & 69,61 & 95,44 & 82,93 & 86,80 & 10,98 & 2,70 & 86,80 & 7,29 & 42,13 & 36,15 & 45,68 \\
$\mathrm{La} / \mathrm{Yb}$ & 7,44 & 3,84 & 7,35 & 6,47 & 10,40 & 4,29 & 0,82 & 10,40 & 17,12 & 8,67 & 4,57 & 16,07 \\
$\mathrm{Ti} / \mathrm{Zr}$ & 82,66 & 80,24 & 53,84 & 72,06 & 28,60 & 81,87 & 103,00 & 28,6 & 61,00 & 82,32 & 100,19 & 68,01 \\
$\mathrm{La} / \mathrm{Nb}$ & 3,61 & 2,82 & 3,68 & 3,35 & 3,20 & 1,03 & 1,07 & 3,20 & 0,77 & 2,11 & 1,79 & 1,78 \\
$\mathrm{Ti} / \mathrm{Y}$ & 351,27 & 271,36 & 265,31 & 229,09 & 124,70 & 378,31 & 271,00 & 124,70 & 593,00 & 432,39 & 373,33 & 373,87 \\
$\mathrm{Ba} / \mathrm{La}$ & 29,90 & 24,50 & 26,16 & 24,72 & 26,90 & 10,70 & 2,52 & 26,90 & 9,46 & 20,02 & 20,17 & 27,03 \\
$\mathrm{Zr} / \mathrm{Nd}$ & 4,74 & 6,40 & 6,49 & 4,39 & 4,80 & 7,80 & 31,76 & 14,50 & 5,80 & 5,71 & 6,74 & 5,05 \\
$\mathrm{La} / \mathrm{Sm}$ & 4,41 & 2,77 & 4,57 & 3,83 & 5,00 & 2,63 & 0,95 & 50,00 & 3,70 & 4,02 & 2,53 \\
\hline
\end{tabular}

GLOSS: global subducting sediment composition.

2009; Girardi et al., 2012) e no Cráton do São Francisco (Girardi et al., 2017).

No presente estudo, a adoção do modelo é baseada em várias evidências. O diagrama multielementar dos diques de Peixoto de Azevedo-Nova Guarita (Figura 9A) é muito semelhante aos diagramas dos enxames Mesoproterozoico Nova Lacerda (Corrêa da Costa et al., 2009), Paleoproterozoico de Carajás (Giovanardi et al., 2019) e Suíte Vespor (Scandolara et al., 2014), fundamentados em dados geoquímicos e isotópicos consistentes que apontam o modelo de subducção e metassomatismo como responsável pelo enriquecimento mantélico. As comparações entre razões de elementos (Tabela 2) com esses enxames dão suporte a essa teoria, sendo particularmente notável a semelhança entre o Peixoto de Azevedo-Nova Guarita, a Suíte Vespor e o enxame de Carajás. A similaridade entre os diagramas e as razões de elementos incompatíveis LILE, LREE, MREE e HFSE (Figura 9 e Tabela 2) de Peixoto de Azevedo-Nova Guarita e o GLOSS indica claramente a influência sedimentar na contaminação do manto. Entre todos os enxames comparados, os diques de Peixoto de Azevedo-Nova Guarita possuem as mais altas razões $\mathrm{Ba} / \mathrm{Nb}, \mathrm{La} / \mathrm{Nb}$ e La/Sm (Tabela 2). A quantidade de Ba nesse enxame é notória. A origem do enriquecimento nesse elemento é controversa. Weaver (1991) o atribui à presença de sedimentos pelágicos, enquanto Plank e Langmuir (1998) não ressaltam diferenças importantes de $\mathrm{Ba}$ em sedimentos pelágicos e terrígenos.

$\mathrm{O}$ exame da Figura 5B acrescenta evidência adicional ao modelo adotado. Condie (2007), utilizando razões de sedimentos subductados obtidos de diferentes ocorrências por Plank e Langmuir (1998), demonstrou que tais amostras se situam acima do campo formado pelo alinhamento N-MORB-E-MORB-OIB, enquanto amostras representativas da crosta basáltica estão situadas dentro do campo de alinhamento MORB-OIB. Nesse diagrama, apenas uma amostra dos diques em estudo situa-se dentro desse campo e representa composição próxima ao E-MORB, enquanto as demais refletem a influência da cobertura sedimentar no manto metassomatizado (Figura 5B).

\section{INFERÊNCIAS GEOTECTÔNICAS E COMPARAÇÃO COM ENXAMES SEMELHANTES DO SUPERCONTINENTE COLUMBIA}

Embora sua posição relativa seja debatida, em virtude de dados paleomagnéticos insuficientes, é consensual a participação da Amazônia na configuração do Supercontinente Columbia ou Nuna, cuja existência ocorreu desde o Paleoprotorozoico tardio até o Mesoproterozoico (Cordani et al., 2009; Bispo-Santos et al., 2012; D'Agrella-Filho et al., 2012, 2015, 2016; Teixeira et al., 2019). Nesse contexto, arcos magmáticos tiveram grande importância na evolução do supercontinente (Hoffman, 1989; Rogers e Santosh, 2002; Pesonen et al., 2003; Rogers e Santosh, 2004; Johansson, 2009; Evans e Mitchell, 2011; Pesonen et al., 2012). No Cráton Amazônico, os diques estudados cortam as rochas paleoproterozoicas, principalmente gnaisses e granitos, cujas idades variam, aproximadamente, entre 1,99 e 1,75 Ga e são pertencentes a arcos magmáticos denominados Cuiú-Cuiú e Juruena (Klein et al., 2001; Vasquez et al., 2002; Duarte et al., 2012; Assis et al., 2017). Embora as amostras utilizadas para este estudo não tenham 
sido datadas, pode-se supor que possuam a mesma idade das amostras a oeste (1419 \pm 3 Ma; Bispo-Santos et al., 2012), na região de Nova Guarita, cujas características de campo e feições petrográficas são idênticas. Elas provêm de intrusão nas mesmas litologias, indicando que possivelmente pertencem ao mesmo enxame, denominado, assim, Peixoto de Azevedo-Nova Guarita. Considerando-se essa idade, os diques máficos de Peixoto de Azevedo-Nova Guarita classificam-se como pós-orogênicos intrudidos após a estabilização da Província Rio Negro-Juruena. Intrusões de diques e soleiras máficos ocorreram durante o Mesoproterozoico a SW do Cráton Amazônico, a exemplo dos enxames da Serra da Providência (1,55 Ga), Nova Lacerda (1,38 Ga), Complexo Colorado (1,35 Ga), como também entre outras regiões do Supercontinente Columbia, quer causados por processos extensivos relacionados à tectônica regional, quer atribuídos diretamente à fragmentação do supercontinente. No estágio supostamente final desse processo, uma série de enxames de diques máficos no período de 1,42 a 1,33 Ga foi estudada no cráton a oeste da África, no Escudo Fennoscandia, Báltica, e no Escudo Greenland, no Canadá.

A Tabela 3 exibe as idades dessas intrusões e daquelas no Cráton Amazônico. À guisa de comparação, três desses enxames foram confrontados com os diques de Peixoto de Azevedo-Nova Guarita. Os diques do cráton a W da África, em Marrocos, denominado de Bas Drâa Inlier (1,38 Ga, El Bahat et al., 2013; ou 1,41 Ga, Söderlund et al., 2013), o sill Midsommerso (1,38 Ga; Upton et al., 2005), a NE da
Groenlândia, e o Michael Gabbro (1,42 Ga; Emslie et al., 1997), na Província Grenville, Canadá, apresentam feições geoquímicas semelhantes às de Peixoto de Azevedo-Nova Guarita, caracterizadas por diagramas multielementares semelhantes (Figura 9) e elevadas razões $\mathrm{Ba} / \mathrm{Nb}, \mathrm{La} / \mathrm{Nb}$ e $\mathrm{La} / \mathrm{Sm}$ (Tabela 2), típicas de enriquecimento mantélico ou contaminação do fuso basáltico por material crustal.

No caso do enxame Bas Drâa Inlier, ambas as hipóteses são consideradas e os diques são diretamente relacionados à fragmentação do Supercontinente Columbia, com provável ação de uma pluma relacionada a um rift intracratônico. $\mathrm{O}$ empobrecimento em $\mathrm{Nb}$ é atribuído à contaminação do manto sublitosférico ou da crosta (El Bahat et al., 2013). Enriquecimento mantélico por subducção é a origem admitida como mais provável do sill Midsommerso, cuja intrusão se deveria à provável ascensão de uma pluma em litosfera extensional (Upton et al., 2005). No período de 1,46 a 1,43 Ga ocorreu, na Província Grenville (Scharer et al., 1986), intensa atividade magmática caracterizada pela intrusão de grandes complexos ígneos com associação de anortositos, mangearitos, charnoquitos e granitos. O Michael Gabbro (1,42 Ga) é, entre os enxames comparados com os diques de Peixoto de Azevedo-Nova Guarita, o que mostra a maior afinidade geoquímica (Figura 9A e Tabela 2), cujas características são atribuídas ou à contaminação do magma basáltico por rochas crustais pertencentes a arcos magmáticos, ou, mais provavelmente, à contaminação mantélica por subducção (Emslie et al., 1997).

Tabela 3. Principais enxames de diques e magmatismos máficos, com idades entre 1,43 e 1,33 Ga, pertencentes aos terrenos que compõem o Supercontinente Columbia.

\begin{tabular}{|c|c|c|c|c|}
\hline & Rocha & Idade (Ma) & Método & Referência \\
\hline \multicolumn{5}{|l|}{ Cráton Amazônico } \\
\hline Figueira Branca & Gabro & $1425 \pm 8 ; 1416 \pm 7$ & $\mathrm{U}-\mathrm{Pb}$ & Teixeira et al. (2011) \\
\hline Indiavaí & Gabro & $1416 \pm 7$ & $\mathrm{U}-\mathrm{Pb}$ & D’Agrella-Filho et al. (2012) \\
\hline Nova Guarita & Diabásio & $1418 \pm 3$ & Ar-Ar & Bispo-Santos et al. (2012) \\
\hline Tapuruquara & Gabro & $1427 \pm 189$ & $\mathrm{Rb}-\mathrm{Sr}$ & Santos et al. (2000) \\
\hline Nova Lacerda & Diabásio & $1380 \pm 32 ; 1387 \pm 17$ & $\mathrm{Rb}-\mathrm{Sr}$ & $\begin{array}{c}\text { Corrêa da Costa et al. (2009); } \\
\text { Teixeira et al. (2016) }\end{array}$ \\
\hline Complexo Colorado & Leucogabro & $1352 \pm 4$ & $\mathrm{U}-\mathrm{Pb}$ & Teixeira et al. (2006) \\
\hline Serra do Cachimbo & Diabásio & $1330 \pm 43$ & $\mathrm{~K}-\mathrm{Ar}$ & Teixeira et al. (1978) \\
\hline \multicolumn{5}{|l|}{ Cráton do oeste da África } \\
\hline Bas Drâa Inlier & Diabásio & $1381 \pm 8 ; 1384 \pm 6$ & $\mathrm{U}-\mathrm{Pb}$ & El Bahat et al. (2013) \\
\hline Bas Drâa Inlier & Diabásio & $1416 \pm 6$ & U-Pb & Söderlund et al. (2013) \\
\hline \multicolumn{5}{|l|}{ Escudo Fennoscandia, Báltica } \\
\hline Axamo & Diabásio & $1410 \pm 10$ & $\mathrm{U}-\mathrm{Pb}$ & Ahall e Connelly (1998) \\
\hline \multicolumn{5}{|l|}{ Escudo Greenland } \\
\hline Midsommerso & Diabásio & $1382 \pm 2$ & $\mathrm{U}-\mathrm{Pb}$ & Upton et al. (2005) \\
\hline \multicolumn{5}{|l|}{ Província Greenville } \\
\hline E. Canada (Michael Gabbro) & Gabro & $1426 \pm 6$ & $\mathrm{U}-\mathrm{Pb}$ & Emslie et al. (1997) \\
\hline
\end{tabular}




\section{CONSIDERAÇÕES FINAIS}

A evolução tectônica do SW do Cráton Amazônico caracterizou-se por acreções por meio de arcos magmáticos, propiciando crescimento crustal e episódicas subducções de litosferas oceânicas desde o Paleoproterozoico até estágios finais do Mesoproterozoico (Cordani e Teixeira, 2007; Teixeira et al., 2011, 2016). Análises isotópicas e principalmente geoquímicas de elementos traços indicaram que as crostas oceânicas subductadas continham frequentemente material crustal ou sedimentos pelágicos, cujos fluidos somados aos da placa oceânica provocaram metassomatismo no peridotito mantélico. Esse foi um mecanismo gerador de fontes mantélicas de vários enxames de diques máficos, principalmente na região SW do referido cráton, onde intrusões máficas paleoproterozoicas da Suíte Vespor (Scandolara et al., 2014) e também de vários enxames mesoproterozoicos - a saber, como na Serra da Providência, Nova Lacerda, Colorado e Nova Brasilândia (Corrêa da Costa et al., 2009; Girardi et al., 2008, 2012, 2013) - , foram geradas intrudindo arcos magmáticos ou placas continentais. O enxame Peixoto de Azevedo-Nova Guarita é mais um exemplo desse processo petrogenético, sendo, nesse caso, intrusivo nos arcos magmáticos Cuiú-Cuiú e Juruena.

Em comparação com outros enxames mesoproterozoicos do Cráton Amazônico, os diques estudados evidenciam a maior contaminação mantélica por fluidos gerados de sedimentos tipo GLOSS, face às altas razões dos elementos LREE/HSFE, LREE/MREE, LREE/HREE e LILE/HSFE representados pelas razões $\mathrm{La} / \mathrm{Nb}, \mathrm{Ce} / \mathrm{Y}, \mathrm{La} / \mathrm{Sm}, \mathrm{La} / \mathrm{Yb}$ e $\mathrm{Ba} / \mathrm{Nb}$. Outra evidência da prevalência desse tipo de fluido em relação ao do tipo OIB, cuja origem pode estar ligada a rochas máficas da placa oceânica ou a uma fonte mais profunda, conforme é sugerida pela posição das amostras no diagrama das razões $\mathrm{Nb} / \mathrm{Y}$ versus $\mathrm{Th} / \mathrm{Yb}$. Tais amostras situam-se acima da faixa de alinhamento mantélico N-MORB - OIB, o que indica a presença de contaminação crustal. À exceção de uma amostra, a maioria delas concentra-se nas proximidades do ponto que representa E-MORB, estando apenas um pouco mais próxima do polo OIB. Comparações com diques máficos de idades semelhantes de outras partes do mundo, como no Canadá, na África e na Groenlândia, considerados originários da fase final da ruptura do Supercontinente Columbia, com idade estimada entre 1,42 e 1,33 Ga, apresentam várias características geoquímicas semelhantes às dos diques mesoproterozoicos do Cráton Amazônico. As interpretações consideradas para os diques dessas regiões são semelhantes às apresentadas paras os diques deste estudo. Tais considerações indicam que o processo de subducção foi efetivo na evolução paleoproterozoica e mesoproterozoica do Cráton Amazônico e na formação da fonte mantélica desses diques, de forma análoga ao que ocorreu em outras regiões do Supercontinente Columbia.

\section{AGRADECIMENTOS}

Os autores agradecem ao Programa de Pós-Graduação em Geociências da UFMT o auxílio no apoio logístico fornecido pela UFMT, ao Laboratório de Laminação e ao Laboratório Multiusuário de técnicas analíticas, ambos da FAGEO/UFMT, e aos professores que auxiliaram no desenvolvimento deste trabalho. O primeiro autor agradece à Coordenação de Aperfeiçoamento de Pessoal de Nível Superior (CAPES) pelo apoio em forma de bolsa de Mestrado. Os autores também agradecem ao Prof. Dr. Wilson Teixeira pelas sugestões apresentadas, e à Fundação de Amparo à Pesquisa do Estado de Mato Grosso (FAPEMAT) e ao Conselho Nacional de Desenvolvimento Científico e Tecnológico (CNPq) pelo suporte financeiro.

\section{REFERÊNCIAS}

Ahall, K. I., Connelly, J. (1998). Intermittent 1.53-1.13 Ga magmatism in western Baltica; age constraints and correlations within a postulated supercontinent. Precambrian Research, 92(1), 1-20. https://doi.org/10.1016/S0301-9268(98)00064-3

Assis, R. R. (2015). Depósitos Auriferos Associados ao Magmatismo Félsico da Província de Alta Floresta (MT), Cráton Amazônico: Litogeoquímica, Idade de Mineralizações e Fonte dos Fluidos. Tese (Doutorado). Campinas: Unicamp. Disponível em: $<$ http://repositorio.unicamp.br/jspui/handle/ REPOSIP/287787>. Acesso em: 9 set. 2020.

Assis, R. R., Xavier, R. P., Creaser, R. A. (2017). Linking the Timing of Disseminated Granite-Hosted Gold-Rich Deposits to Paleoproterozoic Felsic Magmatism at Alta Floresta Gold Province, Amazon Craton, Brazil: Insights from Pyrite and Molybdenite Re-Os Geochronology. Economic Geology, 112(8), 1937-1957. https://doi.org/10.5382/econgeo.2017.4535

Ayers, J. C. (1998). Trace element modeling of aqueous Fluid \pm peridotite interaction in the mantle wedge of subduction zones. Contributions to Mineralogy and Petrology, 132(4), 390-404. https://doi.org/10.1007/s004100050431

Ayers, J. C., Dittmer, S. K., Layne, G. D. (1997). Partitioning of elements between peridotite and $\mathrm{H}_{2} \mathrm{O}$ at 2.0-3.0 GPa and $900-1.100{ }^{\circ} \mathrm{C}$, and application to models of subduction zone processes. Earth and Planetary Science Letters, 150(3-4), 381-398. https://doi.org/10.1016/S0012-821X(97)00096-4

Bastos Leal, L. R., Teixeira, W., Piccirillo, E. M., Menezes Leal, A. B., Girardi, V. A. V. (1994). Geocronologia Rb/ Sr e K/Ar dos enxames de diques máficos de Uauá, Bahia (Brasil). Geochimica Brasiliensis, 8(1), 99-114. http://dx.doi. org/10.21715/gb.v8i1.72 
Bellieni, G., Piccirillo, E. M., Petrini, R., Girardi, V. A. V., Menezes Leal, A. B., Teixeira, W., Bastos Leal, L. R., Min, A. D., Chiaramonti, P. C., Tanner de Oliveira, M. A. F. (1995). Petrological and Sr-Nd evidence bearing on Early Proterozoic magmatic events of the subcontinental mantle: São Francisco craton (Uauá, NE-Brazil). Contributions to Mineralogy and Petrology, 122(3), 252-261. https://doi.org/10.1007/s004100050125

Bispo-Santos, F., D’Agrella-Filho, M. S., Pacca, I. I. G., Janikian, L., Trindade, R. I. F., Elming, S. A., Silva, J. A., Barros, M. A. S., Pinho, F. E. C. (2008). Columbia revisited: Paleomagnetic results from the 1790 Ma colider volcanics (SW Amazonian Craton, Brazil). Precambrian Research, 164(1-2), 40-49. https://doi.org/10.1016/j.precamres.2008.03.004

Bispo-Santos, F., D’Agrella-Filho, M. S., Trindade, R. I. F., Elming, S.-Å., Janikian, L., Vasconcelos, P. M., Perillo, B. M., Pacca, I. I. G., Silva, J. A., Barros, M. A. S. (2012). Tectonic implications of the 1419 Ma Nova Guarita mafic intrusives paleomagnetic pole (Amazonian Craton) on the longevity of Nuna. Precambrian Research, 196-197, 1-22. https://doi.org/10.1016/j.precamres.2011.10.022

Bossi, J., Campal, N., Civetta, L., Demarchi, G., Girardi, V. A. V., Mazzucchelli, M., Negrini, L., Rivalenti, G., Fragoso Cesar, A. R. S., Sinigoi, S., Teixeira, W., Piccirillo, E. M., Molesini, M. (1993). Early Proterozoic dike swarms from western Uruguay: geochemistry, Sr-Nd isotopes and petrogenesis. Chemical Geology, 106(3-4), 263-277. https:// doi.org/10.1016/0009-2541(93)90031-D

Boynton, W. (1984). Cosmochemistry of the Rare Earth Elements: Meteorite Studies. Developments in Geochemistry, 2, 63-114. https://doi.org/10.1016/B978-0-444-42148-7.50008-3

Brenan, J. M., Shaw, H. F., Phinney, D. L., Ryerson, F. J. (1994). Rutile-aqueous fluid partitioning of Nb, Ta, Hf, Zr, U and Th: implications for high field strength element depletions in island-arc basalts. Earth Planetary Science Letters, 128(3-4), 327-339. https://doi.org/10.1016/0012-821X(94)90154-6

Brenan, J. M., Shaw, H. F., Ryerson, F. J., Phinney, D. L. (1995). Mineral-aqueous fluid partitioning of trace elements at $900^{\circ} \mathrm{C}$ and $2.0 \mathrm{GPa}$ : Constraints on the trace element chemistry of mantle and deep crustal fluids. Geochimica et Cosmochimica Acta, 59(16), 3331-3350. https://doi. org/10.1016/0016-7037(95)00215-L

Condie, K. (2007). Accretionary orogens in space and time. In: R. D. Hatcher Jr., M. P. Carlson, J. H. McBride, J. R. M. Catalán (Eds.), Memoir of the Geological Society of America (v. 200, p. 145-158). Geological Society of America. https:// doi.org/10.1130/2007.1200(09)
Cordani, U. G., Teixeira, W. (2007). Proterozoic accretionary belts in the Amazonian Craton. In: R. D. Hatcher Jr., M. P. Carlson, J. H. McBride, J. R. M. Catalán (Eds.), Memoir of the Geological Society of America (v. 200, p. 297-320). Geological Society of America. https://doi.org/10.1130/2007.1200(14)

Cordani, U. G., Teixeira, W., D’Agrella-Filho, M. S., Trindade, R. I. (2009). The position of the Amazonian Craton in supercontinents. Gondwana Research, 15(3-4), 396-407. https://doi.org/10.1016/j.gr.2008.12.005

Cordery, M. J., Davies, G. F., Campbell, I. H. (1997). Genesis of flood basalts from eclogite-bearing mantle plumes. Journal of Geophysical Research, 102(B9), 20179-20198. https:// doi.org/10.1029/97JB00648

Corrêa da Costa, P. C., Carneiro, M. A., Teixeira, W., Girardi, V. A. V., Nalini Júnior, H. A. N., Oliveira, A. H., Fernandes, R. A. (2006). Estudo geoquímico e petrológico dos diques máficos da Região de Candeias-Campo BeloSanto Antônio do Amparo (MG), porção meridional do Craton São Francisco. Geologia USP. Série Científica, 5(2), 65-84. https://doi.org/10.5327/S1519-874X2006000100005

Corrêa da Costa, P. C., Girardi, V. A. V. (2005). Petrology, geochemistry and $\mathrm{Sr}-\mathrm{Nd}$ isotopes of the paleoproterozoic mafic dykes from the Goiás-Crixás Archean Block, Goiás State, Brazil. Revista Brasileira de Geociências, 35(1), 135-150. https://doi.org/10.25249/0375-7536.2005351135150

Corrêa da Costa, P. C., Girardi, V.A. V., Matos, J. B., Ruiz, A. S. (2009). Geocronologia Rb-Sr e Características Geoquímicas dos Diques Máficos da Região de Nova Lacerda e Conquista D Oeste (MT), Porção Sudoeste do Craton Amazônico. Geologia USP. Série Cientifica, 9(1), 115-132. https://doi. org/10.5327/Z1519-874X2009000100008

Corrêa da Costa, P. C., Girardi, V. A. V., Matos, J. B., Ruiz, A. S., Correia, C. T. (2008). Contribuição ao estudo petrológico e geoquímico das rochas máficas-ultramáficas da região de Vila Bela da Santíssima Trindade-MT, Porção Sudoeste do Cráton Amazônico. Geociências, 27(3), 287-298.

D’Agrella Filho, M. S., Bispo-Santos, F., Trindade, R. I. F. (2015). O Cráton Amazônico em supercontinentes: uma visão com base em dados paleomagnéticos. Contribuição à Geologia da Amazônia. Belém: SBG - Núcleo Norte.

D’Agrella-Filho, M. S., Bispo-Santos, F., Trindade, R. I. F., Antonio, P. Y. J. (2016). Paleomagnetism of the Amazonian Craton and its role in paleocontinents. Brazilian Journal of Geology, 46(2), 275-299. https://doi. org/10.1590/2317-4889201620160055 
D’Agrella-Filho, M. S., Trindade, R. I. F., Elming, S.-Å., Teixeira, W., Yokoyama, E., Tohver, E., Geraldes, M. C., Pacca, I. I. G., Barros, M. A. S., Ruiz, A. S. (2012). The 1420Ma Indiavaí Mafic Intrusion (SW Amazonian Craton): Paleomagnetic results and implications for the Columbia supercontinent. Gondwana Research, 22(3-4), 956-973. https://doi.org/10.1016/j.gr.2012.02.022

Dardenne, M. A., Schobbenhaus, C. (2001). Metalogênese do Brasil. Brasília: Ed. Universidade de Brasília. Disponível em: <http://rigeo.cprm.gov.br/jspui/handle/doc/1291>. Acesso em: 9 set. 2020.

Dezula, S. E. M., Barros, M. A. S., Pierosan, R., Santos, J. O. S., Assis, R. R. (2018). Granito Aragão - Suíte intrusiva Nhandú - um granito oxidado, tipo A2, de 1967 a 1964 Ma na Província Aurífera Alta Floresta - Cráton Amazônico. Geologia USP. Série Científica, 18(1), 3-20. https://doi. org/10.11606/issn.2316-9095.v18-434

Duarte, T. B., Lopes, L. B. L., Rizzoto, G. J. (2016). Novos resultados de geocronologia U-Pb (LA-ICP-MS) e Sm-Nd para rochas do Domínio Vulcano-Plutônico no setor Oeste da Provìncia Aurífera Alta Floresta - MT Brasil. XLVIII Congresso Brasileiro de Geologia. Porto Alegre: SBG. p. 843-844. Disponível em: <http://sbgeo.org.br>. Acesso em: 9 set. 2020.

Duarte, T. B., Rodrigues, J. B., Ribeiro, P. S. E., Scandolara, J. E. (2012). Tectonic evolution of the Juruena magmatic arc between the Aripuanã and Juruena rivers: northwest Mato Grosso State, Brazil. Revista Brasileira de Geociências, 42(4), 824-840. https://doi. org/10.25249/0375-7536.2012424824840

El Bahat, A., Ikenne, M., Söderlund, U., Cousens, B., Youbi, N., Ernst, R., Soulaimani, A., El Janati, M., Hafid, A. (2013). U-Pb baddeleyite ages and geochemistry of dolerite dykes in the Bas Drâa Inlier of the Anti-Atlas of Morocco: Newly identified 1380 Ma event in the West African Craton. Lithos, 174, 85-98. https://doi.org/10.1016/j. lithos.2012.07.022

Emslie, R. F., Hamilton, M. A., Gower, C. F. (1997). The Michael Gabbro and other Mesoproterozoic lithospheric probes in southern and central Labrador. Canadian Journal of Earth Science, 34(12), 1566-1580. https://doi.org/10.1139/ e17-127

Ernst, R. E., Bleeker, W., Söderlund, U., Kerr, A. C. (2013). Large Igneous Provinces and supercontinents: Toward completing the plate tectonic revolution. Lithos, 174(4), 1-14. https://doi.org/10.1016/j.lithos.2013.02.017
Ernst, R. E., Buchan, K. L. (2001). Large mafic magmatic events through time and links to mantle-plume heads. In: R. E. Ernst, K. L. Buchan (Eds.), Geological Society of America Special Papers (v. 352, p. 483-575). Geological Society of America. https://doi.org/10.1130/0-8137-2352-3.483

Ernst, R. E., Okrugin, A. V., Veselovskiy, R. V., Kamo, S. L., Hamilton, M. A., Pavlov, V., Söderlund, U., Chamberlain, K. R., Rogers, C. (2016). The 1501 Ma Kuonamka Large Igneous Province of northern Siberia: U-Pb geochronology, geochemistry, and links with coeval magmatism on other crustal blocks. Russian Geology and Geophysics, 57(5), 653-671. https://doi.org/10.1016/j.rgg.2016.01.015

Evans, D. A., Mitchell, R. N. (2011). Assembly and breakup of the core of Paleoproterozoic-Mesoproterozoic supercontinent Nuna. Geology, 39(5), 443-446. https://doi.org/10.1130/ G31654.1

Giovanardi, T., Girardi, V. A. V., Teixeira, W., Mazzucchelli, M. (2019). Mafic dyke swarms at 1882, 535 and $200 \mathrm{Ma}$ in the Carajás region, Amazonian Craton: $\mathrm{Sr}-\mathrm{Nd}$ isotopy, trace element geochemistry and inferences on their origin and geological settings. Journal of South American Earth Science, 92, 197-208. https://doi.org/10.1016/j.jsames.2019.02.017

Girardi, V. A. V., Corrêa da Costa, P. C., Teixeira, W. (2012). Petrology and $\mathrm{Sr}-\mathrm{Nd}$ characteristics of the Nova Lacerda dike swarm, SW Amazonian Craton: new insights regarding its subcontinental mantle source and Mesoproterozoic geodynamics. International Geology Review, 54(2), 165-182. https://doi.org/10.1080/00206814.2010.510238

Girardi, V. A. V., Teixeira, W., Bettencourt, J. S., Andrade, S., Navarro, M. S., Sato, K. (2008). Trace element geochemistry and Sr-Nd characteristics of Mesoproterozoic mafic intrusive rocks from Rondônia, Brazil, SW Amazonian Craton: Petrogenetic and tectonic inferences. Episodes, 31(4), 392-400. https://doi.org/10.18814/epiiugs/2008/v31i4/004

Girardi, V. A. V., Teixeira, W., Mazzucchelli, M., Corrêa da Costa, P. C. (2013). Sr-Nd constraints and trace-elements geochemistry of selected Paleo and Mesoproterozoic mafic dikes and related intrusions from the South American Platform: Insights into their mantle sources and geodynamic implications. Journal of South American Earth Science, 41, 65-82. https://doi.org/10.1016/j.jsames.2012.09.006

Girardi, V. A. V, Teixeira, W., Oliveira, E. P., Corrêa da Costa, P. C. (2017). São Francisco Craton, Eastern Brazil. In: M. Heilbron, U. G. Cordani, F. F. Alkmim (Eds.), São Francisco Craton, Eastern Brazil (p. 145-169). Suíça: Springer. https:// doi.org/10.1007/978-3-319-01715-0 
Halls, H. C. (1982). The importance and potential of mafic dyke swarms in studies of geodynamic processes. Geoscience Canada, 9(3), 145-154.

Hoffman, P. F. (1989). Speculations on Laurentia's first gigayear (2.0 to $1.0 \mathrm{Ga}$ ). Geology, 17(2), 135-138. https://doi. org/10.1130/0091-7613(1989)017<0135:SOLSFG>2.3.CO;2

Hofmann, A. W. (2007). Sampling mantle heterogeneity through oceanic basalts: isotopes and trace elements. Treatise of Geochemistry, 2, 1-44. https://doi.org/10.1016/ B0-08-043751-6/02123-X

Iacumin, M., Min, A. D., Piccirillo, E. M., Bellieni, G. (2003). Source mantle heterogeneity and its role in the genesis of Late Archaean-Proterozoic (2.7-1.0 Ga) and Mesozoic (200 and $130 \mathrm{Ma}$ ) tholeiitic magmatism in the South American Platform. Earth-Science Reviews, 62(3-4), 365-397. https:// doi.org/10.1016/S0012-8252(02)00163-0

Iacumin, M., Piccirillo, E. M., Girardi, V. A. V., Teixeira, W., Bellieni, G., Echeveste, H., Fernandez, R., Pinese, J. P. P., Ribot, A. (2001). Early Proterozoic Calc-Alkaline and Middle Proterozoic Tholeiitic Dyke Swarms from CentralEastern Argentina: Petrology, Geochemistry, Sr-Nd Isotopes and Tectonic Implications. Journal of Petrology, 42(11), 2109-2143. https://doi.org/10.1093/petrology/42.11.2109

Irvine, T. N. J., Baragar, W. (1971). A guide to the chemical classification of the common volcanic rocks. Canadian Journal of Earth Sciences, 8(5), 523-548. https://doi.org/10.1139/e71-055

Janousek, V., Farrow, C. M., Erban, V. (2003). GCDkit: New PC software for interpretation of whole-rock geochemical data from igneous rocks. Geochimica et Cosmochimica Acta, 67, 186.

Jaques, A. L., Green, D. H. (1979). Determination of liquid compositions in high-pressure melting of peridotite. American Mineralogist, 64(11-12), 1312-1321.

Jaques, A. L., Green, D. H. (1980). Anhydrous Melting of Peridotite at $0-15 \mathrm{~Kb}$ Pressure and the Genesis of Tholeiitic Basaits. Contributions to Mineralogy and Petrology, 73(4), 287-310. https://doi.org/10.1007/BF00381447

Johansson, Å. (2009). Baltica, Amazonia and the SAMBA connection-1000 million years of neighbourhood during the Proterozoic? Precambrian Research, 175(1-4), 221-234. https://doi.org/10.1016/j.precamres.2009.09.011

Klein, E. M. (2004). Geochemistry of the igneous oceanic crust. In: H. D. Holland, K. K. Turekian (Eds.), Treatise on Geochemistry (v. 3, p. 433-463). Amsterdam: Elsevier.
Klein, E. M., Almeida, M. E., Vasquez, M. L., Bahia, R. B. C., Santos, M. L. E., Ferreira, A. L. (2001). Geologia e recursos minerais da Provincia Mineral do Tapajós. Folhas Vila Mamãe Anã (SB.21-V-D), Jacareacanga (SB.21-Y-B), Caracol (SB.21-X-X), Vila Riozinho (SB.21-Z-A) e Rio Novo (SB.21-Z-C). Estados do Pará e Amazonas. Escala 1:500.000. Brasília: CPRM/DIEDIG/DEPAT, 81 p.

Kushiro, I. (2001). Partial melting experiments on peridotite and origin of mid-ocean ridge basalt. Annual Review of Earth and Planetary Sciences, 29, 71-107. https://doi.org/10.1146/ annurev.earth.29.1.71

Kuyumjian, R. M. (1998). Mafic dike swarms of the Goiás massif, central Brazil. Revista Brasileira de Geociências, 28(1), 45-50. Disponível em: <http://www.ppegeo.igc. usp.br/index.php/rbg/article/view/11191>. Acesso em: 10 set. 2020 .

Lacerda Filho, J. V., Abreu Filho, W., Valente, C. R., Oliveira, C. C., Albuquerque, M. C. (Eds.). (2004). Geologia e Recursos Minerais do Estado de Mato Grosso: texto explicativo dos mapas geológicos e de recursos minerais do Estado de Mato Grosso. MME/CPRM/SICME-MT (Programa Integração, Atualização e Difusão de Dados da Geologia do Brasil e Subprograma Mapas Geológicos estaduais, escala 1:1.000.000). Cuiabá: MME/CPRM/SICME-MT. v. 1. p. 235.

Le Bas, M. J., Maitre, R. W., Streckeisen, A., Zanettin, B., IUGS. (1986). A chemical classification of volcanic rocks based on the total alkali-silica diagram. Journal of Petrology, 27(3), 745-750. https://doi.org/10.1093/petrology/27.3.745

Mazzucchelli, M., Rivalenti, G., Menezes Leal, A., Girardi, V. A. V., Brito Neves, B. B., Teixeira, W. (2000). Petrology of metabasaltic dykes in the Diamantina region, Minas Gerais, Brazil. Periodico di Mineralogia, 70(2), 231-254.

Mazzucchelli, M., Rivalenti, G., Piccirillo, E. M., Girardi, V.A. V., Civetta, L., Petrini, R. (1995). Petrology of the Proterozoic mafic dyke swarms of Uruguay and constraints on their mantle source composition. Precambrian Research, 74(3), 177-194. https://doi.org/10.1016/0301-9268(95)00014-V

McDonough, W. F., Sun, S.-S. (1995). The composition of the Earth. Chemical Geology, 120(3-4), 223-253. https:// doi.org/10.1016/0009-2541(94)00140-4

Menezes Leal, A. B., Bellieni, G., Girardi, V. A. V., Bastos Lea, L. R., Teixeira, W., Piccirillo, E. M. (1995). Contribuição ao estudo petrológico e geoquímico dos enxames de diques máficos de Uauá, Bahia, Brasil. Geochimica Brasiliensis, 9(1), 61-90. http://doi.org/10.21715/gb.v9i1.84 
Menezes Leal, A. B., Girardi, V. A. V., Bastos Leal, L. R. (2000). Petrologia e geoquimica do magmatismo básico mesozóico da suite básica Apoteri, estado de Roraima-Brasil. Geochimica Brasiliensis, 14(1), 155-174. http://doi. org/10.21715/gb.v14i1.173

Miguel Jr., E. (2011). Mineralizações auríferas do lineamento Peru-Trairão Província Auríifera de Alta Floresta-MT. Dissertação (Mestrado). Campinas: UNICAMP. Disponível em: $<$ http://repositorio.unicamp.br/jspui/handle/ REPOSIP/287618>. Acesso em: 10 set. 2020.

Moraes Brito, C., Bellieni, G., Comin-Chiaramonti, P., Melfi, A. J., Piccirillo, E. M., Tanner de Oliveira, M. A. F. (1989). Mafic dykes of Salvador (State of Bahia, Brazil): geological and petrological characteristics. Boletim IG-USP. Série Científica, 20,9-14. https://doi.org/10.11606/issn.2316-8986.v20i0p9-14

Moreton, L. C., Martins, E. G. (Eds.). (2005). Geologia e Recursos Minerais da Folha Vila Guarita - Folha SC.21-Z-B. Escala 1:250.000. Brasil: CPRM/DEPAT/DIEDIG. v. 1.68 p.

Mori, P. E., Reeves, S., Correia, C. T., Haukka, A. M. (1999). Development of a Fused Glass Disc XRF facility and comparison with the pressed powder pellet technique at Institute of Geoscience, São Paulo University. Revista Brasileira de Geociências, 29(3), 441-446. https://doi.org/10.25249/0375-7536.199929441446

Moura, M. A. (1998). O Maciço Granítico Matupáe o Depósito de Ouro Serrinha (MT): Petrologia, Alteração Hidrotermal e Metalogenia. Tese (Doutorado). Brasília: UnB. Disponível em: $<$ http://repositorio.unb.br/handle/10482/8040>. Acesso em: 10 set. 2020.

Moura, M. A., Botelho, N. F., Olivo, G. R., Kyser, T. K. (2006). Granite-related Paleoproterozoic, Serrinha gold deposit, Southern Amazonia, Brazil: hydrothermal alteration, fluid inclusion and stable isotope constraints on genesis and evolution. Econonic Geology, 101(3), 585-605. https://doi. org/10.2113/gsecongeo.101.3.585

Navarro, M. S., Andrade, S., Ulbrich, H., Gomes, C. B., Girardi, V. A. V. (2008). The Direct Determination of Rare Earth Elements in Basaltic and Related Rocks using ICP-MS: Testing the Efficiency of Microwave Oven Sample Decomposition Procedures. Geostandards and Geoanalytical Research, 32(2), 167-180. https://doi. org/10.1111/j.1751-908X.2008.00840.x

Paes de Barros, A. J. (2007). Granitos da região de Peixoto de Azevedo - Novo Mundo e mineralizações auriferas relacionadas - Província Aurifera Alta Floresta (MT). Tese (Doutorado). Campinas: UNICAMP. Disponível em: $<$ http://
repositorio.unicamp.br/jspui/handle/REPOSIP/287713>. Acesso em: 10 set. 2020.

Pearce, J. A. (2008). Geochemical fingerprinting of oceanic basalts with applications to ophiolite classification and the search for Archean oceanic crust. Lithos, 100(1-4), 14-48. https://doi.org/10.1016/J.LITHOS.2007.06.016

Pearce, T. H. (1968). A contribution to the theory of variation diagrams. Contributions to Mineralogy and Petrology, 19, 142-157. https://doi.org/10.1007/BF00635485

Pesonen, L. J., Elming, S.-Å., Mertanen, S., Pisarevsky, S., D'Agrella-Filho, M. S., Meert, J. G., Schmidt, P. W., Abrahamsen, N., Bylund, G. (2003). Palaeomagnetic configuration of continents during the Proterozoic. Tectonophysics, 375(1-4), 289-324. https://doi.org/10.1016/ S0040-1951(03)00343-3

Pesonen, L. J., Mertanen, S., Veikkolainen, T. (2012). PaleoMesoproterozoic Supercontinents - A Paleomagnetic View. Geophysica, 48(1-2), 5-48.

Pimentel, M. M., Botelho, N. F. (2001). Geologia e Evolução Tectônica da Região Norte do Mato Grosso (Projeto ProminAlta Floresta). VII Simpósio de Geologia da Amazônia. Belém: SBG, Núcleo-Norte.

Pinho, M. A. S. B. (2002). Proposta para nova terminologia estratigráfica para rochas vulcanoplutônicas paleoproterozoicas do norte do estado de Mato Grosso, porção ocidental sul do Craton Amazônico. Revista Brasileira de Geociências, 32(1), 153-156. https://doi.org/10.25249/0375-7536.2002321153156

Pinho, M. A. S. B., Chemale Jr., F., Van Schmus, W. R., Pinho, F. E. C. (2003). U-Pb and Sm-Nd evidence for 1.76-1.77 Ga magmatism in the Moriru region, Mato Grosso, Brazil: implications for province boundaries in the SW Amazon Craton. Precambrian Research, 126(1-2), 1-25. https://doi. org/10.1016/S0301-9268(03)00126-8

Pinho, M. A. S. B., Lima, E. F., Fetter, W. A., Van Schmus, W. R., Chemale Jr., F. (2001). Caracterização petrográfica e dados geocronológicos preliminares das rochas vulcânicas da Formação Iriri porção centro-sul do Cráton Amazônico - Aripuanã - Mato Grosso. Revista Brasileira de Geociências, 31(1), 37-42. https://doi. org/10.25249/0375-7536.20013113742

Plank, T., Langmuir, C. H. (1998). The chemical composition of subducting sediment and its consequences for the crust and mantle. Chemical Geology, 145(3-4), 325-394. https:// doi.org/10.1016/S0009-2541(97)00150-2 
Prado, E. S., Barros, M. A. S., Pinho, F. E. C., Pierosan, R. (2013). Granito Terra Nova-petrologia e geocronologia: um granito tipo-A da Província Aurífera Alta Floresta-Cráton Amazônico. Revista Brasileira de Geociências, 43(1), 101-116. https://doi.org/10.5327/Z2317-48892013000100009

Rivalenti, G., Mazzucchelli, M., Girardi, V.A. V., Cavazzini, G., Finatti, C., Barbieri, M. A., Teixeira, W. (1998). Petrogenesis of the paleoproterozoic basalt-andesit-rhyolite dyke association in the Carajás region. Amazonian Craton. Lithos, 43(4), 235-265. https://doi.org/10.1016/S0024-4937(98)00015-2

Rivalenti, G., Mazzucchelli, M., Molesini, M., Petrini, R., Girardi, V. A. V., Bossi, J., Campal, N. (1995). Petrology of late proterozoic mafic dikes in the Nico Perez region, central Uruguay. Mineralogy and Petrology, 55(4), 239-263. https:// doi.org/10.1007/BF01165120

Rogers, J. J. W., Santosh, M. (2002). Configuration of Columbia, a Mesoproterozoic supercontinent. Gondwana Research, 5(1), 5-22. https://doi.org/10.1016/S1342-937X(05)70883-2

Rogers, J. J. W., Santosh, M. (2004). Continents and Supercontinents. New York: Oxford University Press.

Santos, F. S., Pierosan, R., Barros, M. A. S., Geraldes, M. C., Faustino de Lima, M. (2019). Petrology of the Colíder Group volcanic successions in the northernmost Mato Grosso, Brazil: A contribution to the knowledge of the felsic volcanism of the Alta Floresta Gold Province. Journal of South American Earth Sciences, 89, 10-29. https://doi. org/10.1016/j.jsames.2018.10.007

Santos, J. O. S., Hartmann, L. A., Gaudette, H. E., Groves, D. I., Mcnaughton, N. J., Fletcher, I. R. (2000). A New Understanding of the Provinces of the Amazon Craton Based on Integration of Field Mapping and U-Pb and Sm-Nd Geochronology. Gondwana Research, 3(4), 453-488. https:// doi.org/10.1016/S1342-937X(05)70755-3

Scandolara, J. E., Ribeiro, P. S. E., Frasca, A. A. S., Fuck, R. A., Rodrigues, J. B. (2014). Geochemistry and geochronology of mafic rocks from the Vespor suite in the Juruena arc, Roosevelt-Juruena terrain, Brazil: Implications for Proterozoic crustal growth and geodynamic setting of the SW Amazonian craton. Journal of South American Earth Sciences, 53, 20-49. https://doi.org/10.1016/j.jsames.2014.04.001

Scharer, U., Krogh, T. E., Gower, C. F. (1986). Age and evolution of the Grenville Province in eastern Labrador from U-Pb systematics in accessory minerals. Contributions to Mineralogy and Petrology, 94, 438-451. https://doi. org/10.1007/BF00376337
Silva, F. R., Barros, M. A. S., Pierosan, R., Pinho, F. E. C., Rocha, M. L. B. P., Vasconcelos, B. R., Dezula, S. E. M., Tavares, C., Rocha, J. (2014). Geoquímica e geocronologia U-Pb (SHRIMP) de granitos da região de Peixoto de Azevedo: Província Aurífera Alta Floresta, Mato Grosso. Brazilian Journal of Geology, 44(3), 433-455. https://doi.org/10.5327/ Z2317-4889201400030007

Silva, G. H., Leal, J. W. L., Montalvão, R. M. G., Bezerra, P. E. L., Pimenta, O. N. S., Tassinari, C. C. G., Fernandes, C. A. C. (1980). Geologia da Folha SC.21 - Juruena. In: DNPM (Ed.), Projeto RADAMBRASIL. Folha SC.21 Juruena; geologia, geomorfologia, pedologia, vegetação e uso potencial da terra (p. 21-116). Rio de Janeiro: DNPM.

Silva, M. G., Abram, M. B. (2008). Projeto Metalogenia da Província Aurifera Juruena - Teles Pires, Mato Grosso. Goiânia: CPRM, Programa Geologia do Brasil (Informe de Recursos Minerais). v. 1. p. 212 p.

Söderlund, U., Ibanez-Mejia, M., El Bahat, A., Ernst, R. E., Ikenne, M., Soulaimani, A., Youbi, N., Cousens, B., El Janati, M., Hafid, A. (2013). Reply to Comment on "U-Pb baddeleyite ages and geochemistry of dolerite dykes in the Bas-Drâa inlier of the Anti-Atlas of Morocco: Newly identified 1380Ma event in the West African Craton" by André Michard and Dominique Gasquet. Lithos, 174, 101-108. https://doi. org/10.1016/j.lithos.2013.04.003

Souza, J. P., Frasca, A. A. S., Oliveira, C. C. (2005). Geologia e Recursos Minerais da Província Mineral de Alta Floresta. Relatório Integrado. Goiânia: CPRM, Programa Levantamentos Geológicos Básicos do Brasil (Projeto Província Mineral de Alta Floresta). v. 1. 159 p.

Sun, S., McDonough, W. F. (1989). Chemical and isotopic systematics of oceanic basalts: implications for mantle composition and processes. Geological Society, London, Special Publication, 42(1), 313-345. https://doi.org/10.1144/ GSL.SP.1989.042.01.19

Takahashi, E., Kushiro, I. (1983). Melting of a dry peridotite at high pressures and basalt magma genesis. American Mineralist, 68(9-10), 859-879.

Takahahshi, E., Nakajima, K., Wright, T. L. (1998). Origin of the Columbia River basalts: melting model of a heterogeneous plume head. Earth and Planetary Science Letters, 162(1-4), 63-80. https://doi.org/10.1016/S0012-821X(98)00157-5

Tassinari, C.C. G., Macambira, M. J. B. (1999). Geochronological provinces of the Amazonian Craton. Episodes, 22(3), 174-182. https://doi.org/10.18814/epiiugs/1999/v22i3/004 
Tassinari, C. C. G., Macambira, M. J. B. (2004). A Evolução Tectônica do Cráton Amazônico. In: Geologia do continente sul-americano: evolução da obra de F. F. M. de Almeida (p. 470-485). São Paulo: Beca.

Teixeira, W. (1978). Significação tectônica do magmatismo anorogênico básico e alcalino na região amazônica. Dissertação (Mestrado). São Paulo: Instituto de Geociências, USP. https:// doi.org/10.11606/D.44.1978.tde-02042015-141224

Teixeira, W., Bettencourt, J. S., Girardi, V. A. V., Onoe, A., Sato, K., Rizzotto, G. J. (2006). Mesoproterozoic mantle heterogeneity in the SW Amazonian Craton: $40 \mathrm{Ar} / 39 \mathrm{Ar}$ and $\mathrm{Nd}-\mathrm{Sr}$ isotopic evidence from maficfelsic rocks, In: Dyke Swarms - Time Markers of Crustal Evolution. London: Taylor \& Francis Group. https://doi. org/10.13140/2.1.1473.8888

Teixeira, W., Ernst, R. E., Hamilton, M. A., Lima, G. A., Ruiz, A. S., Geraldes, M. C. (2016). Widespread ca. $1.4 \mathrm{Ga}$ intraplate magmatism and tectonics in a growing Amazonia. Geologiska Föreningen, 138(1), 241-254. https://doi.org/1 $0.1080 / 11035897.2015 .1042033$

Teixeira, W., Geraldes, M. C., D'Agrella-Filho, M. S., Santos, J. O. S., Sant'Ana Barros, M. A., Ruiz, A. S., Corrêa da Costa, P. C. (2011). Mesoproterozoic juvenile maficultramafic magmatism in the SW Amazonian Craton (Rio Negro-Juruena province): SHRIMP U-Pb geochronology and $\mathrm{Nd}-\mathrm{Sr}$ constraints of the Figueira Branca Suite. Journal of South American Earth Sciences, 32(4), 309-323. https:// doi.org/10.1016/j.jsames.2011.04.011

Teixeira, W., Hamilton, M. A., Girardi, V. A. V., Faleiros, F. M., Ernst, R. E. (2019). U-Pb baddeleyite ages of key dyke swarms in the Amazonian Craton (Carajás/Rio Maria and Rio Apa areas) Tectonic implications for events at 1880,
$1110 \mathrm{Ma}, 535 \mathrm{Ma}$ and $200 \mathrm{Ma}$. Precambrian Research, 329, 138-155. https://doi.org/10.1016/j.precamres.2018.02.008

Teixeira, W., Tassinari, C. C. G., Cordani, U. G., Kawashita, K. (1989). A review of the geochronology of the Amazonian Craton: Tectonic implications. Precambrian Research, 42(3-4), 213-227. https://doi.org/10.1016/0301-9268(89)90012-0

Trindade Netto, G. B., Corrêa da Costa, P. C., Girardi, V.A. V. (2016). Contribuição à geologia, petrografia e geoquímica dos diques máficos da porção centro-leste de Rondônia, sudoeste do Cráton Amazônico. Geologia USP. Série Científica, 16(1), 3-21. http://doi.org/10.11606/issn.2316-9095.v16ilp3-21

Upton, B. G. J., Ramo, O. T., Heaman, L. M., BlichertToft, J., Kalsbeek, F., Barry, T. L., Jepsen, H. F. (2005). The Mesoproterozoic Zig-Zag Dal basalts and associated intrusions of eastern North Greenland: mantle plume-lithosphere interaction. Contributions to Mineralogy and Petrology, 149, 40-56. https://doi.org/10.1007/s00410-004-0634-7

Vasquez, M. L., Ricci, P. S. F., Klein, E. L. (2002). Granitóides pós-colisionais da porção leste da Província Tapajós. In: E. L. Klein, M. L. Vasquez, L. T. Rosa-Costa (Eds.), Contribuições à geologia da Amazônia (v. 3, p. 67-83). Belém: SBG-Núcleo Norte.

Wang, C. Y., Zhou, M.-F., Keays, R. R. (2006). Geochemical constraints on the origin of the Permian Baimazhai maficultramafic intrusion, SW China. Contributions to Mineralogy and Petrology, 152, 309-321. https://doi.org/10.1007/ s00410-006-0103-6

Weaver, B. L. (1991). The origin of ocean island basalt endmember compositions: trace element and isotopic constraints. Earth and Planetary Science Letters, 104(2-4), 381-397. https://doi.org/10.1016/0012-821X(91)90217-6 